\title{
1 Disorder is a critical component of lipoprotein sorting in Gram-negative bacteria
}

2

3 Jessica El Rayes ${ }^{1,2 \$}$, Joanna Szewczyk ${ }^{1,2 \$}$, Michael Deghelt ${ }^{1,2}$, André Matagne ${ }^{3}$, Bogdan I.

4 Iorga $^{4}$, Seung-Hyun Cho ${ }^{1,2}$, and Jean-François Collet ${ }^{1,2^{*}}$

$7 \quad{ }^{1}$ WELBIO, Avenue Hippocrate 75, 1200 Brussels, Belgium.

$8{ }^{2}$ de Duve Institute, Université catholique de Louvain, Avenue Hippocrate 75, 1200 Brussels,

9 Belgium.

$10{ }^{3}$ Centre d'ingéniérie des Protéines, Institut de Chimie B6, Université de Liège, Allée de la 11 Chimie 3, 4000 Liège, Sart Tilman, Belgium.

$12{ }^{4}$ Université Paris-Saclay, CNRS UPR 2301, Institut de Chimie des Substances Naturelles, 1391198 Gif-sur-Yvette, France.

14

15 Both authors contributed equally to the work

16

$17 *$ *Correspondence: jfcollet@uclouvain.be 
Abstract (150 max)

20 Gram-negative bacteria express structurally diverse lipoproteins in their envelope. Here

21 we found that approximately half of lipoproteins destined to the Escherichia coli outer 22 membrane display an intrinsically disordered linker at their N-terminus. Intrinsically 23 disordered regions are common in proteins, but establishing their importance in vivo has 24 remained challenging. Here, as we sought to unravel how lipoproteins mature, we 25 discovered that unstructured linkers are required for optimal trafficking by the Lol 26 lipoprotein sorting system: linker deletion re-routes three unrelated lipoproteins to the 27 inner membrane. Focusing on the stress sensor ResF, we found that replacing the linker 28 with an artificial peptide restored normal outer membrane targeting only when the 29 peptide was of similar length and disordered. Overall, this study reveals the role played 30 by intrinsic disorder in lipoprotein sorting, providing mechanistic insight into the 31 biogenesis of these proteins and suggesting that evolution can select for intrinsic disorder 32 that supports protein function. 


\section{Introduction}

The cell envelope is the morphological hallmark of Escherichia coli and other Gram-negative bacteria. It is composed of the inner membrane, a classical phospholipid bilayer, as well as the outer membrane, an asymmetric bilayer with phospholipids in the inner leaflet and lipopolysaccharides in the outer leaflet ${ }^{1}$. This lipid asymmetry enables the outer membrane to function as a barrier that effectively prevents the diffusion of toxic compounds in the environment into the cell. The inner and outer membranes are separated by the periplasm, a viscous compartment that contains a thin layer of peptidoglycan also known as the cell wall ${ }^{1}$. The cell envelope is essential for growth and survival, as illustrated by the fact that several antibiotics such as the $\beta$-lactams target mechanisms of envelope assembly. Mechanisms involved in envelope biogenesis and maintenance are therefore attractive targets for novel antibacterial strategies.

Approximately one-third of E. coli proteins are targeted to the envelope, either as soluble proteins present in the periplasm or as proteins inserted in one of the two membranes ${ }^{2}$. While inner membrane proteins cross the lipid bilayer via one or more hydrophobic $\alpha$-helices, proteins inserted in the outer membrane generally adopt a $\beta$-barrel conformation ${ }^{3}$. Another important group of envelope proteins is the lipoproteins, which are globular proteins anchored to one of the two membranes by a lipid moiety. Lipoproteins carry out a variety of important functions in the cell envelope: they participate in the biogenesis of the outer membrane by inserting lipopolysaccharide molecules ${ }^{4,5}$ and $\beta$-barrel proteins ${ }^{6}$, they function as stress sensors triggering signal transduction cascades when envelope integrity is altered ${ }^{7}$, and they control processes that are important for virulence ${ }^{8}$. The diverse roles played by lipoproteins in the cell envelope has drawn a lot of attention lately, revealing how crucial these proteins are in a wide range of vital processes and identifying them as attractive targets for antibiotic development. Yet, a detailed 
understanding of the mechanisms involved in lipoprotein maturation and trafficking is still missing.

Lipoproteins are synthesized in the cytoplasm as precursors with an N-terminal signal peptide ${ }^{9}$. The last four C-terminal residues of this signal peptide, known as the lipobox, function as a molecular determinant of lipid modification unique to bacteria; only the cysteine at the last position of the lipobox is strictly conserved ${ }^{10}$. After secretion of the lipoprotein into the periplasm, the thiol side-chain of the cysteine is first modified with a diacylglyceryl moiety by prolipoprotein diacylglyceryl transferase (Lgt) ${ }^{9}$ (Extended Data Fig. 1a, step 1). Then, signal peptidase II (LspA) catalyzes cleavage of the signal peptide N-terminally of the lipidated cysteine before apolipoprotein $\mathrm{N}$-acyltransferase (Lnt) adds a third acyl group to the $\mathrm{N}$-terminal amino group of the cysteine (Extended Data Fig. 1a, steps 2-3). Most mature lipoproteins are then transported to the outer membrane by the Lol system. Lol consists of LolCDE, an ABC transporter that extracts lipoproteins from the inner membrane and transfers them to the soluble periplasmic chaperone LolA (Extended Data Fig. 1a, steps 4-5) ${ }^{11}$. LolA escorts lipoproteins across the periplasm, binding their hydrophobic lipid tail, and delivers them to the outer membrane lipoprotein LolB (Extended Data Fig. 1a, step 6). LolB finally anchors lipoproteins to the inner leaflet of the outer membrane using a mechanism that remains poorly characterized (Extended Data Fig. 1a, step 7).

In most Gram-negative bacteria, a few lipoproteins remain in the inner membrane ${ }^{12,13}$. The current view is that inner membrane retention depends on the identity of the two residues located immediately downstream of the N-terminal cysteine on which the lipid moiety is attached $^{14}$; this sequence, two amino acids in length, is known as the Lol sorting signal. When lipoproteins have an aspartate at position +2 and an aspartate, glutamate, or glutamine at 
83 position +3 , they remain in the inner membrane ${ }^{15,16}$, possibly because strong electrostatic maturation remained to be elucidated, we sought to identify novel molecular determinants controlling lipoprotein biogenesis. First, we systematically analyzed the sequence of the 66 107 lipoproteins with validated localization ${ }^{27}$ encoded by the E. coli $\mathrm{K} 12$ genome $^{27}$ and found that interactions between the +2 aspartate and membrane phospholipids prevent their interaction with LolCDE ${ }^{17}$. However, this model is largely based on data obtained in E. coli and variations have been described in other bacteria. For instance, in the pathogen Pseudomonas aeruginosa, an aspartate is rarely found at position +2 and inner membrane retention appears to be determined by residues +3 and $+4^{18,19}$. Surprisingly, lipoproteins are well sorted in $P$. aeruginosa cells expressing the E. coli LolCDE complex ${ }^{20}$, despite their different Lol sorting signal. This result cannot be explained by the current model of lipoprotein sorting, underscoring that our comprehension of the precise mechanism that governs the triage of lipoproteins remains incomplete.

Excitingly, more unresolved questions regarding lipoprotein biogenesis have recently been raised. First, it was reported that a LolA-LolB-independent trafficking route to the outer membrane exists in $E$. coli ${ }^{21}$, but the factors involved have remained unknown. Second, although lipoproteins have traditionally been considered to be exposed to the periplasm in $E$. coli and many other bacterial models ${ }^{9}$, a series of investigations have started to challenge this view by identifying lipoproteins on the surface of E. coli, Vibrio cholerae, and Salmonella Typhimurium $^{22-26}$. Overall, the field is beginning to explore a lipoprotein topological landscape that is more complex than previously assumed and raising intriguing questions about the signals that control surface targeting and exposure.

Here, stimulated by the hypothesis that crucial details of the mechanisms underlying lipoprotein 
108 half of the outer membrane lipoproteins display a long and intrinsically disordered linker at

109 their N-terminus. Intrigued by these unstructured segments, we then probed their importance

110 for the biogenesis of RcsF, NlpD, and Pal, three structurally and functionally unrelated outer

111 membrane lipoproteins. Unexpectedly, we found that deleting the linker-while keeping the

112 Lol sorting signal intact — altered the targeting of all three lipoproteins to the outer membrane,

113 with physiological consequences. Focusing on RcsF, we determined that both the length and

114 disordered character of the linker were important. Remarkably, lowering the load of the Lol

115 system by deleting lpp, which encodes the most abundant lipoprotein $(\sim 1$ million copies per

116 cell $^{28}$ ), restored normal outer membrane targeting of linker-less RcsF, indicating that the N-

117 terminal linker is required for optimal lipoprotein processing by Lol. Taken together, these

118 observations reveal the unsuspected role played by protein intrinsic disorder in lipoprotein

119 biogenesis. 
Results

Half of $E$. coli lipoproteins present long disordered segments at their N-termini

123 In an attempt to discover novel molecular determinants controlling the biogenesis of

124 lipoproteins, we decided to systematically analyze the sequence of the lipoproteins encoded by

125 the E. coli genome (strain MG1655) in search of unidentified structural features. E. coli encodes $\sim 80$ validated lipoproteins ${ }^{29}$, of which 58 have been experimentally shown to localize in the

127 outer membrane ${ }^{27}$. Comparative modeling of existing X-ray, cryogenic electron microscopy

128 (cryo-EM), and nuclear magnetic resonance (NMR) structures revealed that approximately half

129 of these outer membrane lipoproteins display a long segment ( $>22$ residues) that is predicted to

130 be disordered at the N-terminus (Fig. 1, Extended Data Fig. 2, Extended Data Table 1). In contrast, only one of the 8 lipoproteins that remain in the inner membrane (DcrB; Extended

Data Fig. 2, Extended Data Table 1) had a long, disordered linker, suggesting that disordered

133 peptides may be important for lipoprotein sorting.

Deleting the N-terminal linker of ResF, NIpD, and Pal perturbs their targeting to the outer membrane

137 Intrigued by the presence of these N-terminal disordered segments in so many outer membrane 138 lipoproteins, we decided to investigate their functional importance. We selected three 139 structurally unrelated lipoproteins whose function could easily be assessed: the stress sensor

140 RcsF (which triggers the Rcs signaling cascade when damage occurs in the envelope ${ }^{30}$ ), NlpD

141 (which activates the periplasmic $\mathrm{N}$-acetylmuramyl-L-alanine amidase AmiC, which is involved 142 in peptidoglycan cleavage during cell division ${ }^{31,32}$ ), and the peptidoglycan-binding lipoprotein $143 \mathrm{Pal}$ (which is important for outer membrane constriction during cell division ${ }^{33}$ ). 
145 We began by preparing truncated versions of RcsF, NlpD, and Pal devoid of their N-terminal unstructured linkers (Extended Data Fig. 1b, Extended Data Fig. 2; RcsF $\mathrm{F}_{\Delta 19-47}, \mathrm{Pal}_{\Delta 26-56}$, and

$\left.147 \mathrm{NlpD}_{\Delta 29-64}\right)$. Note that the lipidated cysteine residue $(+1)$ and the Lol sorting signal (the amino 148 acids at positions +2 and +3 ) were not altered in $\mathrm{RcsF}_{\Delta 19-47}, \mathrm{Pal}_{\Delta 26-56}$, and $\mathrm{NlpD}_{\Delta 29-64}$, nor in any 149 of the constructs discussed below (Extended Data Table 2). For Pal, although the unstructured

150 linker spans residues 25-68 (Fig. 1), we used Pal ${ }_{\Delta 26-56}$ because $\mathrm{Pal}_{\Delta 25-68}$ was either degraded or not detected by the antibody (data not shown). We first tested whether the truncated lipoproteins were still correctly extracted from the inner membrane and transported to the outer membrane. The membrane fraction was prepared from cells expressing the three variants independently, 154 and the outer and inner membranes were separated using sucrose density gradients (Methods).

155 Whereas wild-type RcsF, NlpD, and Pal were mostly detected (>90\%) in the outer membrane fraction, as expected, $\sim 50 \%$ of $\mathrm{RcsF}_{\Delta 19-47}$ and $\sim 60 \%$ of $\mathrm{NlpD}_{\Delta 29-64}$ were retained in the inner membrane (Fig. 2a, 2b). The sorting of Pal was also affected, although to a lesser extent: 15\% of $\mathrm{Pal}_{\Delta 26-56}$ was retained in the inner membrane (Fig. 2c). Notably, the expression levels of the

159 three linker-less variants were similar $\left(\mathrm{NlpD}_{\Delta 29-64}\right)$ or lower $\left(\mathrm{RcsF}_{\Delta 19-47} ; \mathrm{Pal}_{\Delta 26-56}\right)$ than those of 160 the wild-type proteins (Extended Data Fig. 3), indicating that accumulation in the inner membrane did not result from increased protein abundance.

We then tested the impact of linker deletion on the function of these three proteins. In cells 164 expressing $\mathrm{RcsF}_{\Delta 19-47}$, the Rcs system was constitutively turned on (Fig. 2d); when RcsF 165 accumulates in the inner membrane, it becomes available for interaction with IgaA, its 166 downstream Rcs partner in the inner membrane ${ }^{30,34}$. Likewise, expression of NlpD $\mathrm{D}_{\Delta 29-64}$ did not 167 rescue the chaining phenotype (Fig. 2e) ${ }^{35}$ exhibited by cells lacking both $n l p D$ and envC, an 168 activator of the amidases $\mathrm{AmiA}$ and $\mathrm{AmiB}^{32}$. Finally, $\mathrm{Pal}_{\Delta 26-56}$ partially rescued the sensitivity 169 of the pal mutant to SDS-EDTA that results from increased membrane permeability ${ }^{36}$ (Fig. 2f). 
170 However, this observation needs to be considered with caution given that $\mathrm{Pal}_{\Delta 26-56}$ seemed to

171 be expressed at lower levels than wild-type Pal (Extended Data Fig. 3). Thus, preventing

172 normal targeting of RcsF, NlpD and Pal to the outer membrane had functional consequences.

174 ResF variants with unstructured artificial linkers of similar lengths are normally targeted

\section{5 to the outer membrane}

176 The results above were surprising because they revealed that the normal targeting of RcsF,

$177 \mathrm{NlpD}$, and Pal to the outer membrane does not only require an appropriate Lol sorting signal,

178 as proposed by the current model for lipoprotein sorting ${ }^{9}$, but also the presence of an N-terminal

179 linker. We selected RcsF, whose accumulation in the inner membrane can be easily tracked by

180 monitoring Rcs activity ${ }^{30,37}$, to investigate the structural features of the linker controlling

181 lipoprotein maturation; keeping as little as $10 \%$ of the total pool of RcsF molecules in the inner membrane is sufficient to fully activate $\operatorname{Rcs}^{30}$.

184 We first tested whether changing the sequence of the $\mathrm{N}$-terminal segment while preserving its

185 disordered character still yielded normal targeting of the protein to the outer membrane. To that end, we prepared an RcsF variant in which the N-terminal linker was replaced by an artificial,

4) of similar length and consisting mostly of GS repeats $\left(\mathrm{RcsF}_{\mathrm{GS}}\right)$. Substituting the wild-type linker with this artificial sequence was remarkably well tolerated by $\mathrm{RcsF}$ : $\mathrm{RcsF}_{\mathrm{GS}}$ was targeted

190 normally to the outer membrane (Fig. 3a) and did not constitutively activate the stress system

191 (Fig. 3b). Thus, although $\mathrm{RcsF}_{\mathrm{GS}}$ has an N-terminus with a completely different primary structure, it behaved like the wild-type protein. 
194 We then investigated whether the N-terminal linker required a minimal length for proper

195 targeting and function. We therefore constructed two RcsF variants with shorter, unstructured,

196 artificial linkers $\left(\mathrm{RcsF}_{\mathrm{GS} 2}\right.$ and $\mathrm{RcsF}_{\mathrm{GS} 3}$, with linkers of 18 and 10 residues, respectively;

197 Extended Data Table 2, Extended Data Fig. 2, Extended Data Fig. 4). Importantly, RcsF $\mathrm{GS}_{2}$

198 and, to a greater extent, $\mathrm{RcsF}_{\mathrm{GS} 3}$ did not properly localize to the outer membrane: the shorter

199 the linker, the more RcsF remained in the inner membrane (Fig. 3a). Consistent with the amount

200 of $\mathrm{RcsF}_{\mathrm{GS} 2}$ and $\mathrm{RcsF}_{\mathrm{GS} 3}$ retained in the inner membrane, Rcs activation levels were inversely

201 related to linker length (Fig. 3b).

202

203 The disordered character of the linker is required for normal targeting

204 Taken together, the results above demonstrated that the RcsF linker can be replaced with an 205 artificial sequence lacking secondary structure, provided that it is of appropriate length. Next, we sought to directly probe the importance of having a disordered linker by replacing the RcsF

207 linker with an alpha-helical segment 35 amino acids long from the periplasmic chaperone FkpA $208\left(\operatorname{RcsF}_{\mathrm{FkpA}}\right.$; Extended Data Table 2, Extended Data Fig. 2, Extended Data Fig. 4). 209 Introducing order at the N-terminus of RcsF dramatically impacted the protein distribution 210 between the two membranes: $\mathrm{RcsF}_{\mathrm{FkpA}}$ was substantially retained in the inner membrane (Fig. 211 3c) and constitutively activated Rcs (Fig. 3d). As alpha-helical segments are considerably 212 shorter than unstructured sequences containing a similar number of amino acids, we also 213 prepared an $\mathrm{RcsF}$ variant $\left(\mathrm{RcsF}_{\mathrm{col}}\right)$ with a longer alpha helix from the helical segment of colicin 214 Ia, which is 73 amino acids in length and also predicted to remain folded in the $\mathrm{RcsF}_{\text {col }}$ construct 215 (Extended Data Table 2, Extended Data Fig. 2, Extended Data Fig. 4). However, doubling 216 the size of the helix had no impact, with $\operatorname{RcsF}_{\text {col }}$ behaving similarly to $\operatorname{RcsF}_{\mathrm{FkpA}}$ (Fig. 3c, 3d). 217 Together, these data demonstrate that having an N-terminal disordered linker downstream of 218 the Lol sorting signal is required to correctly target RcsF to the outer membrane. The length of 
the linker is important, but the sequence is not, on the condition that the linker does not fold into a defined secondary structure.

\section{The disordered linker is required for optimal processing by Lol}

223

Our finding that $\mathrm{N}$-terminal disordered linkers function as molecular determinants of the targeting of lipoproteins to the outer membrane raised the question of whether these linkers work in a Lol-dependent or Lol-independent manner. To address this mechanistic question, we tested the impact of deleting $l p p$ on the targeting of $\mathrm{RcsF}_{\Delta 19-47}$. The lipoprotein Lpp, also known as the Braun lipoprotein, covalently tethers the outer membrane to the peptidoglycan and controls the size of the periplasm ${ }^{38,39}$. Being expressed at $\sim 1$ million copies per cell ${ }^{28}$, Lpp is numerically the most abundant protein in E. coli. Thus, by deleting lpp, we considerably decreased the load on the Lol system by removing its most abundant substrate. Remarkably, lpp deletion fully rescued the targeting of $\mathrm{RcsF}_{\Delta 19-47}$ to the outer membrane (Fig. 4a), indicating that the linker functions in a Lol-dependent manner and suggesting that accumulation of $\mathrm{RcsF}_{\Delta 19-47}$ in the inner membrane results from a decreased ability of the Lol system to process the linker-less RcsF variant. Importantly, similar results were obtained with $\mathrm{NlpD}_{\Delta 29-64}$, which was also correctly targeted to the outer membrane in cells lacking Lpp (Fig. 4a). Pal ${ }_{\Delta 26-56}$ could not be tested because membrane fractionation failed with lpp pal double mutant cells whether or not they expressed $\mathrm{Pal}_{\Delta 26-56}$ (data not shown).

To obtain further insights into the mechanism at play here, we next monitored whether linker deletion impacted the transfer of RcsF from LolA to LolB in vitro. LolA with a C-terminal Histag was expressed in the periplasm of cells expressing wild-type $\mathrm{RcsF}$ or $\mathrm{RcsF}_{\Delta 19-47}$ and purified to near homogeneity via affinity chromatography (Methods; Extended Data Fig. 5). Both RcsF and $\mathrm{RcsF}_{\Delta 19-47}$ were detected in immunoblots of the fractions containing purified LolA 
244 (Extended Data Fig. 5), indicating that both proteins form a soluble complex with LolA and

245 confirming that they use this chaperone for transport across the periplasm. LolB was expressed

246 as a soluble protein in the cytoplasm and purified by taking advantage of a C-terminal Strep-

247 tag; LolB was then incubated with LolA-RcsF or LolA-RcsF $F_{\Delta 19-47}$ and pulled-down using

248 Streptactin beads (Methods). As both $\mathrm{RcsF}$ and $\mathrm{RcsF}_{\Delta 19-47}$ were detected in the LolB-containing

249 pulled-down fractions (Fig. 4b), we conclude that both proteins were transferred from LolA to

250 LolB. Thus, the linker is not required for the transfer of RcsF from LolA to LolB.

252 Finally, we focused on the LolCDE ABC transporter in charge of extracting outer membrane

253 lipoproteins and transferring them to LolA. Over-expression (Extended Data Fig. 6a) of all

254 components of this complex failed to rescue normal targeting of $\operatorname{RcsF}_{\Delta 19-47}$ to the outer

255 membrane (Extended Data Fig. 6b). Likewise, over-expressing the enzymes involved in

256 lipoprotein maturation (Lgt, LspA, and Lnt; Fig. 1) had no impact on membrane targeting

257 (Extended Data Fig. 7a, 7b). Thus, taken together, our results suggest that retention of $\mathrm{RcsF}_{\Delta 19-}$

$258{ }_{47}$ in the inner membrane does not result from the impairment of a specific step, but rather from

259 less efficient processing of the truncated lipoprotein by the entire lipoprotein maturation 260 pathway (see Discussion). 


\section{Discussion}

263 Lipoproteins are crucial for essential cellular processes such as envelope assembly and 264 virulence. However, despite their functional importance and their potential as targets for new 265 antibacterial therapies, we only have a vague understanding of the molecular factors that control 266 their biogenesis. By discovering the role played by N-terminal disordered linkers in lipoprotein 267 sorting, this study adds an important new layer to our comprehension of lipoprotein biogenesis in Gram-negative bacteria. Critically, it also indicates that the current model of lipoprotein sorting - that sorting between the two membranes is controlled by the 2 or 3 residues that are adjacent to the lipidated cysteine ${ }^{40}$ —needs to be revised. Lipoproteins with unstructured linkers at their N-terminus are commonly found in Gram-negative bacteria including many pathogens (see below); further work will be required to determine whether these linkers control lipoprotein targeting in organisms other than E. coli, laying the foundation for designing new antibiotics.

It was previously shown that both $l o l A$ and $l o l B$ (but not $l o l C D E$ ) can be deleted under specific conditions $^{21}$, suggesting at least one alternate route for the transport of lipoproteins across the periplasm and their delivery to the outer membrane. During this investigation, we envisaged the possibility that the linker could be required to transport lipoproteins via a yet-to-beidentified pathway independent of LolA/LolB. However, our observations that both RcsF and

$280 \operatorname{RcsF}_{\Delta 19-47}$ were found in complex with LolA (Extended Data Fig. 5) and were transferred by 281 LolA to LolB (Fig. 4b) does not support this hypothesis. Instead, our data clearly indicate that 282 lipoproteins with N-terminal linkers still depend on the Lol system for extraction from the inner membrane and transport to the outer membrane (Extended Data Fig. 1a); they also suggest that N-terminal linkers improve lipoprotein processing by Lol (see below). 
286 We note that two of the lipoproteins under investigation here, Pal and RcsF, have been reported

287 to be surface-exposed ${ }^{30,41,42}$. A topology model has been proposed to explain how RcsF reaches

288 the surface: the lipid moiety of RcsF is anchored in the outer leaflet of the outer membrane

289 while the N-terminal linker is exposed on the cell surface before being threaded through the

290 lumen of $\beta$-barrel proteins ${ }^{42}$. Thus, in this topology, the linker allows RcsF to cross the outer

291 membrane. It is therefore tempting to speculate that N-terminal disordered linkers may be used

292 by lipoproteins as a structural device to cross the outer membrane and reach the cell surface. It

293 is worth noting that N-terminal linkers are commonly found in lipoproteins expressed by the

294 pathogens Borrelia burgdorferi and Neisseria meningitides ${ }^{24,43,44}$; lipoprotein surface exposure

295 is common in these pathogens. In addition, the accumulation of $\mathrm{RcsF}_{\Delta 19-47}$ in the inner

296 membrane (Fig. 2a) also suggests that Lol may be using N-terminal linkers to recognize

297 lipoproteins destined to the cell surface before their extraction from the inner membrane in 298 order to optimize their targeting to the machinery exporting them to their final destination 299 (BAM in the case of $\mathrm{RcsF}^{30,42,45}$ ). Investigating whether a dedicated Lol-dependent route exists 300 for surface-exposed lipoproteins will be the subject of future research.

302 Our work also delivers crucial insights into the functional importance of disordered segments 303 in proteins in general. Most proteins are thought to present portions that are intrinsically 304 disordered. For instance, it is estimated that $30-50 \%$ of eukaryotic proteins contain regions that 305 do not adopt a defined secondary structure in vitro ${ }^{46}$. However, demonstrating that these 306 unstructured regions are functionally important in vivo is challenging. By showing that an N307 terminal disordered segment downstream of the Lol signal is required for the correct sorting of 308 lipoproteins, our work provides direct evidence that evolution has selected intrinsic disorder by 309 function. 
311 In conclusion, the data reported here establish that the triage of lipoproteins between the inner

312 and outer membranes is not solely controlled by the Lol sorting signal; additional molecular

313 determinants, such as protein intrinsic disorder, are also involved. Our data further highlight

314 the previously unrecognized heterogeneity of the important lipoprotein family and call for a

315 careful evaluation of the maturation pathways of these lipoproteins.

\section{DATA AVAILABILITY}

All data generated or analysed during this study are included in this published article and its

supplementary information file.

\section{REFERENCES}

1. Silhavy, T.J., Kahne, D. \& Walker, S. The bacterial cell envelope. Cold Spring Harb Perspect Biol 2, a000414 (2010).

2. Weiner, J.H. \& Li, L. Proteome of the Escherichia coli envelope and technological challenges in membrane proteome analysis. Biochim Biophys Acta 1778, 1698-713 (2008).

3. Ricci, D.P. \& Silhavy, T.J. Outer Membrane Protein Insertion by the $\beta$-barrel Assembly Machine. EcoSal Plus 8(2019).

4. Chimalakonda, G. et al. Lipoprotein LptE is required for the assembly of LptD by the beta-barrel assembly machine in the outer membrane of Escherichia coli. Proc NatI Acad Sci U S A 108, 2492-7 (2011).

5. Sherman, D.J. et al. Lipopolysaccharide is transported to the cell surface by a membrane-to-membrane protein bridge. Science 359, 798-801 (2018).

6. Malinverni, J.C. et al. YfiO stabilizes the YaeT complex and is essential for outer membrane protein assembly in Escherichia coli. Mol Microbiol 61, 151-64 (2006).

7. Laloux, G. \& Collet, J.F. "Major Tom to ground control: how lipoproteins communicate extra-cytoplasmic stress to the decision center of the cell". J Bacteriol (2017).

8. Kovacs-Simon, A., Titball, R.W. \& Michell, S.L. Lipoproteins of bacterial pathogens. Infect Immun 79, 548-61 (2011).

9. Szewczyk, J. \& Collet, J.F. The Journey of Lipoproteins Through the Cell: One Birthplace, Multiple Destinations. Adv Microb Physiol 69, 1-50 (2016).

10. Babu, M.M. et al. A database of bacterial lipoproteins (DOLOP) with functional assignments to predicted lipoproteins. J Bacteriol 188, 2761-73 (2006).

11. Narita, S.I. \& Tokuda, H. Bacterial lipoproteins; biogenesis, sorting and quality control. Biochim Biophys Acta Mol Cell Biol Lipids 1862, 1414-1423 (2017).

12. Horler, R.S., Butcher, A., Papangelopoulos, N., Ashton, P.D. \& Thomas, G.H. EchoLOCATION: an in silico analysis of the subcellular locations of Escherichia coli 
proteins and comparison with experimentally derived locations. Bioinformatics 25, 163-6 (2009).

13. Tokuda, $\mathrm{H}$. Biogenesis of outer membranes in Gram-negative bacteria. Biosci Biotechnol Biochem 73, 465-73 (2009).

14. Tokuda, H. \& Matsuyama, S. Sorting of lipoproteins to the outer membrane in E. coli. Biochim Biophys Acta 1694, IN1-9 (2004).

15. Gennity, J.M. \& Inouye, M. The protein sequence responsible for lipoprotein membrane localization in Escherichia coli exhibits remarkable specificity. J Biol Chem 266, 16458-64 (1991).

16. Terada, M., Kuroda, T., Matsuyama, S.I. \& Tokuda, H. Lipoprotein sorting signals evaluated as the LolA-dependent release of lipoproteins from the cytoplasmic membrane of Escherichia coli. J Biol Chem 276, 47690-4 (2001).

17. Hara, T., Matsuyama, S. \& Tokuda, H. Mechanism underlying the inner membrane retention of Escherichia coli lipoproteins caused by Lol avoidance signals. J Biol Chem 278, 40408-14 (2003).

18. Narita, S. \& Tokuda, H. Amino acids at positions 3 and 4 determine the membrane specificity of Pseudomonas aeruginosa lipoproteins. J Biol Chem 282, 13372-8 (2007).

19. Lewenza, S., Mhlanga, M.M. \& Pugsley, A.P. Novel inner membrane retention signals in Pseudomonas aeruginosa lipoproteins. J Bacteriol 190, 6119-25 (2008).

20. Lorenz, C., Dougherty, T.J. \& Lory, S. Correct Sorting of Lipoproteins into the Inner and Outer Membranes of Pseudomonas aeruginosa by the Escherichia coli LoICDE Transport System. mBio 10(2019).

21. Grabowicz, M. \& Silhavy, T.J. Redefining the essential trafficking pathway for outer membrane lipoproteins. Proc Natl Acad Sci U S A 114, 4769-4774 (2017).

22. Konovalova, A. \& Silhavy, T.J. Outer membrane lipoprotein biogenesis: Lol is not the end. Philos Trans R Soc Lond B Biol Sci 370(2015).

23. Wilson, M.M. \& Bernstein, H.D. Surface-Exposed Lipoproteins: An Emerging Secretion Phenomenon in Gram-Negative Bacteria. Trends Microbiol 24, 198-208 (2016).

24. Zuckert, W.R. Secretion of bacterial lipoproteins: through the cytoplasmic membrane, the periplasm and beyond. Biochim Biophys Acta 1843, 1509-16 (2014).

25. Pride, A.C., Herrera, C.M., Guan, Z., Giles, D.K. \& Trent, M.S. The outer surface lipoprotein VolA mediates utilization of exogenous lipids by Vibrio cholerae. MBio 4, e00305-13 (2013).

26. Valguarnera, E., Scott, N.E., Azimzadeh, P. \& Feldman, M.F. Surface Exposure and Packing of Lipoproteins into Outer Membrane Vesicles Are Coupled Processes in Bacteroides. mSphere 3(2018).

27. Sueki, A., Stein, F., Savitski, M.M., Selkrig, J. \& Typas, A. Systematic Localization of Escherichia coli Membrane Proteins. mSystems 5(2020).

28. Li, G.W., Burkhardt, D., Gross, C. \& Weissman, J.S. Quantifying absolute protein synthesis rates reveals principles underlying allocation of cellular resources. Cell 157, 624-35 (2014).

29. Gonnet, P., Rudd, K.E. \& Lisacek, F. Fine-tuning the prediction of sequences cleaved by signal peptidase II: a curated set of proven and predicted lipoproteins of Escherichia coli K-12. Proteomics 4, 1597-613 (2004).

30. Cho, S.H. et al. Detecting Envelope Stress by Monitoring beta-Barrel Assembly. Cell 159, 1652-64 (2014). 
31. Heidrich, $\mathrm{C}$. et al. Involvement of $\mathrm{N}$-acetylmuramyl-L-alanine amidases in cell separation and antibiotic-induced autolysis of Escherichia coli. Mol Microbiol 41, 16778 (2001).

32. Uehara, T., Parzych, K.R., Dinh, T. \& Bernhardt, T.G. Daughter cell separation is controlled by cytokinetic ring-activated cell wall hydrolysis. EMBO J 29, 1412-22 (2010).

33. Gerding, M.A., Ogata, Y., Pecora, N.D., Niki, H. \& de Boer, P.A. The trans-envelope Tol-Pal complex is part of the cell division machinery and required for proper outermembrane invagination during cell constriction in E. coli. Mol Microbiol 63, 1008-25 (2007).

34. Hussein, N.A., Cho, S.H., Laloux, G., Siam, R. \& Collet, J.F. Distinct domains of Escherichia coli lgaA connect envelope stress sensing and down-regulation of the Rcs phosphorelay across subcellular compartments. PLoS Genet 14, e1007398 (2018).

35. Tsang, M.J., Yakhnina, A.A. \& Bernhardt, T.G. NlpD links cell wall remodeling and outer membrane invagination during cytokinesis in Escherichia coli. PLoS Genet 13, e1006888 (2017).

36. Shrivastava, R., Jiang, X. \& Chng, S.S. Outer membrane lipid homeostasis via retrograde phospholipid transport in Escherichia coli. Mol Microbiol 106, 395-408 (2017).

37. Farris, C., Sanowar, S., Bader, M.W., Pfuetzner, R. \& Miller, S.I. Antimicrobial peptides activate the Rcs regulon through the outer membrane lipoprotein RcsF. J Bacteriol 192, 4894-903 (2010).

38. Cohen, E.J., Ferreira, J.L., Ladinsky, M.S., Beeby, M. \& Hughes, K.T. Nanoscale-length control of the flagellar driveshaft requires hitting the tethered outer membrane. Science 356, 197-200 (2017).

39. Asmar, A.T. et al. Communication across the bacterial cell envelope depends on the size of the periplasm. PLoS Biol 15, e2004303 (2017).

40. Grabowicz, M. Lipoprotein Transport: Greasing the Machines of Outer Membrane Biogenesis: Re-Examining Lipoprotein Transport Mechanisms Among Diverse GramNegative Bacteria While Exploring New Discoveries and Questions. Bioessays 40, e1700187 (2018).

41. Michel, L.V. et al. Dual orientation of the outer membrane lipoprotein Pal in Escherichia coli. Microbiology 161, 1251-9 (2015).

42. Konovalova, A., Perlman, D.H., Cowles, C.E. \& Silhavy, T.J. Transmembrane domain of surface-exposed outer membrane lipoprotein RcsF is threaded through the lumen of beta-barrel proteins. Proc Natl Acad Sci U S A 111, E4350-8 (2014).

43. Brooks, C.L., Arutyunova, E. \& Lemieux, M.J. The structure of lactoferrin-binding protein $B$ from Neisseria meningitidis suggests roles in iron acquisition and neutralization of host defences. Acta Crystallogr F Struct Biol Commun 70, 1312-7 (2014).

44. Noinaj, N. et al. Structural basis for iron piracy by pathogenic Neisseria. Nature 483, 53-8 (2012).

45. Rodriguez-Alonso, R. et al. Structural insight into the formation of lipoprotein-betabarrel complexes. Nat Chem Biol 16, 1019-1025 (2020).

46. Bardwell, J.C. \& Jakob, U. Conditional disorder in chaperone action. Trends Biochem Sci 37, 517-25 (2012). 
47. Majdalani, N., Hernandez, D. \& Gottesman, S. Regulation and mode of action of the second small RNA activator of RpoS translation, RprA. Mol Microbiol 46, 813-26 (2002).

48. Baba, T. et al. Construction of Escherichia coli K-12 in-frame, single-gene knockout mutants: the Keio collection. Mol Syst Biol 2, 20060008 (2006).

49. Cherepanov, P.P. \& Wackernagel, W. Gene disruption in Escherichia coli: TcR and $\mathrm{KmR}$ cassettes with the option of Flp-catalyzed excision of the antibiotic-resistance determinant. Gene 158, 9-14 (1995).

50. Gil, D. \& Bouche, J.P. ColE1-type vectors with fully repressible replication. Gene 105, 17-22 (1991).

51. $\mathrm{Yu}, \mathrm{D}$. et al. An efficient recombination system for chromosome engineering in Escherichia coli. Proc Natl Acad Sci U S A 97, 5978-83 (2000).

52. Sklar, J.G. et al. Lipoprotein SmpA is a component of the YaeT complex that assembles outer membrane proteins in Escherichia coli. Proc Natl Acad Sci U S A 104, 6400-5 (2007).

53. Miller, J.C. Experiments in Molecular Genetics, (Cold Spring Harbor Laboratory Press, New York, 1972).

54. Šali, A. \& Blundell, T.L. Comparative Protein Modelling by Satisfaction of Spatial Restraints. Journal of Molecular Biology 234, 779-815 (1993).

55. Pettersen, E.F. et al. UCSF Chimera - A visualization system for exploratory research and analysis. Journal of Computational Chemistry 25, 1605-1612 (2004).

56. Guzman, L.M., Belin, D., Carson, M.J. \& Beckwith, J. Tight regulation, modulation, and high-level expression by vectors containing the arabinose PBAD promoter. $J$ Bacteriol 177, 4121-30 (1995).

\section{ACKNOWLEDGMENTS}

We thank Asma Boujtat for technical help. We are indebted to the members of the Collet laboratory and to Nassos Typas (EMBL, Heidelberg) for helpful suggestions and discussions and to Tom Silhavy (Princeton) for providing bacterial strains. J.S. was a research fellow of the FRIA and J.F.C. is an Investigator of the FRFS-WELBIO. This work was funded by the WELBIO, by grants from the F.R.S.-FNRS, from the Fédération Wallonie-Bruxelles (ARC 17/22-087), from the European Commission via the International Training Network Train2Target (721484), and from the EOS Excellence in Research Program of the FWO and FRS-FNRS (G0G0818N). 
478 J.-F.C., J.E.R., J.S., and S.H.C. designed and performed the experiments. J.E.R., J.S., and

479 S.H.C. constructed the strains and cloned the constructs. J.-F.C., J.E.R., J.S., S.H.C., and A.M.

480 analyzed and interpreted the data. B.I.I. performed the structural analysis. J.-F.C., J.E.R., and

481 J.S. wrote the manuscript. All authors discussed the results and commented on the manuscript. 
FIGURE LEGENDS

483

Figure 1. Structural analysis of lipoproteins reveals that half of outer membrane

\section{lipoproteins display an intrinsically disordered linker at the $\mathbf{N}$-terminus.}

Structures were generated via comparative modeling (Methods). X-ray and cryo-EM structures

are green, NMR structures are cyan, and structures built via comparative modeling from the closest analog in the same PFAM group are orange. In all cases, the N-terminal linker is in Extended Data Figure 2.

492

Figure 2. The N-terminal linker displayed by lipoproteins is important for outer

a, b, c. The outer membrane (OM) and inner membrane (IM) were separated via centrifugation in a three-step sucrose density gradient (Methods). While (c) $\mathrm{RcsF}_{\mathrm{WT}}$, (d) $\mathrm{NlpD}_{\mathrm{WT}}$, and (e)

$497 \mathrm{Pal}_{\mathrm{WT}}$ were found predominantly in the $\mathrm{OM}, \mathrm{RcsF}_{\Delta 19-47}, \mathrm{NlpD}_{\Delta 29-64}$, and $\mathrm{Pal}_{\Delta 26-56}$ were 498 substantially retained in the IM. Data are presented as the ratio of signal intensity in a single 499 fraction to the total intensity in all fractions. All variants were expressed from plasmids (Extended Data Table 4). DsbD and Lpp were used as controls for the OM and IM, 501 respectively. d. The Rcs system is constitutively active when RcsF's linker is missing. Rcs 502 activity was measured with a beta-galactosidase assay in a strain harboring a transcriptional $503 \operatorname{rpr} A::$ lacZ fusion (Methods). Results were normalized to expression levels of RcsF variants 504 (mean \pm standard deviation; $\mathrm{n}=6$ biologically independent experiments) e. Phase-contrast 505 images of the envC::kan $\Delta n l p D$ mutant complemented with $\mathrm{NlpD} \mathrm{WT}_{\mathrm{T}}$ or $\mathrm{NlpD}_{\Delta 29-64 .} \mathrm{NlpD}_{\Delta 29-64}$ 506 only partially rescues the chaining phenotype of the envC::kan $\Delta n l p D$ double mutant. Scale 
bar, $5 \mu \mathrm{m}$. f. Expression of $\mathrm{Pal}_{\Delta 26-56}$ does not rescue the sensitivity of the pal::kan mutant to SDS-EDTA. Cells were grown in LB medium at $37{ }^{\circ} \mathrm{C}$ until $\mathrm{OD}_{600}=0.5$. Tenfold serial

511 biological triplicates. Graphs in $\mathbf{a}, \mathbf{b}$, and $\mathbf{c}$ were created by spline analysis of curves

512 representing a mean of three independent experiments.

514 Figure 3. The length and the disordered character of the ResF linker play key roles in

\section{ResF targeting to the outer membrane.}

516 a. The outer membrane (OM) and inner membrane (IM) were separated via centrifugation in a

517 three-step sucrose density gradient (Methods). DsbD and Lpp were used as controls for the OM

518 and IM, respectively. The longer the linker, the more protein was correctly translocated to the

519 IM. Bar graphs denote mean \pm standard deviation of $\mathrm{n}=3$ biologically independent

520 experiments. Images are representative of experiments and immunoblots performed in

521 biological triplicate. b. Rcs activity was measured with a beta-galactosidase assay in a strain

522 harboring a transcriptional $\operatorname{rpr} A: \because \operatorname{lac} Z$ fusion (Methods). Results were normalized to expression

523 levels of RcsF variants (mean \pm standard deviation of $n=6$ biologically independent

RcsF mutants harboring alpha helical linkers $\left(\operatorname{RcsF}_{\mathrm{FkpA}}\right.$ and $\left.\mathrm{RcsF} \mathrm{F}_{\mathrm{col}}\right)$ were subjected to two

526 consecutive centrifugations in sucrose density gradients (Methods). Both mutants were

527 inefficiently translocated from the IM to the OM (mean \pm standard deviation of $\mathrm{n}=3$

528 biologically independent experiments). Images are representative of experiments and immunoblots performed in biological triplicate. $\mathbf{d}$. The Rcs system was constitutively active in

$530 \mathrm{RcsF}_{\mathrm{FkpA}}$ and $\mathrm{RcsF}_{\mathrm{col}}$ strains; activation levels were comparable to those of $\mathrm{RcsF}_{\Delta 19-47}$. Rcs

531 activity was measured as in $\mathbf{b}$. Results were normalized as in $\mathbf{b}$. 
Figure 4. N-terminal disordered linkers interact with the Lol system to target lipoproteins

to the outer membrane.

535 a. Deleting Lpp rescues normal targeting of $\mathrm{RcsF}_{\Delta 19-47}$ and $\mathrm{NlpD}_{\Delta 29-64}$ to the outer membrane.

536 The outer and inner membranes were separated via centrifugation in a sucrose density gradient

537 (Methods). Whereas $\mathrm{RcsF}_{\Delta 19-47}$ and $\mathrm{NlpD}_{\Delta 29-64}$ accumulate in the inner membrane of cells 538 expressing Lpp, the most abundant Lol substrate, they are normally targeted to the outer

539 membrane in cells lacking Lpp (mean \pm standard deviation of $\mathrm{n}=3$ biologically independent

540 experiments). b. In vitro pull-down experiments show that $\mathrm{RcsF}_{\mathrm{WT}}$ and $\mathrm{RcsF}_{\Delta 19-47}$ are

541 transferred from LolA to LolB. LolA-RcsF ${ }_{\mathrm{WT}}$ and LolA- $\mathrm{RcsF}_{\Delta 19-47}$ complexes were obtained

542 by LolA-His affinity chromatography followed by size exclusion chromatography (Methods).

543 Each complex was incubated with LolB-Strep that was previously purified via Strep-Tactin

544 affinity chromatography (Methods). Both RcsF variants were eluted in complex with LolB-

545 strep, while LolA was only present in the flow through. I, input; FT, flow through; E, eluate. 
bioRxiv preprint doi: https://doi.org/10.1101/2021.01.05.425367: this version posted January 5, 2021. The copyright holder for this preprint (which was not certified by peer review) is the author/funder, who has granted bioRxiv a license to display the preprint in perpetuity. It is made available under aCC-BY-NC-ND 4.0 International license.

\section{FIGURES}

\section{$548 \quad$ Figure 1}
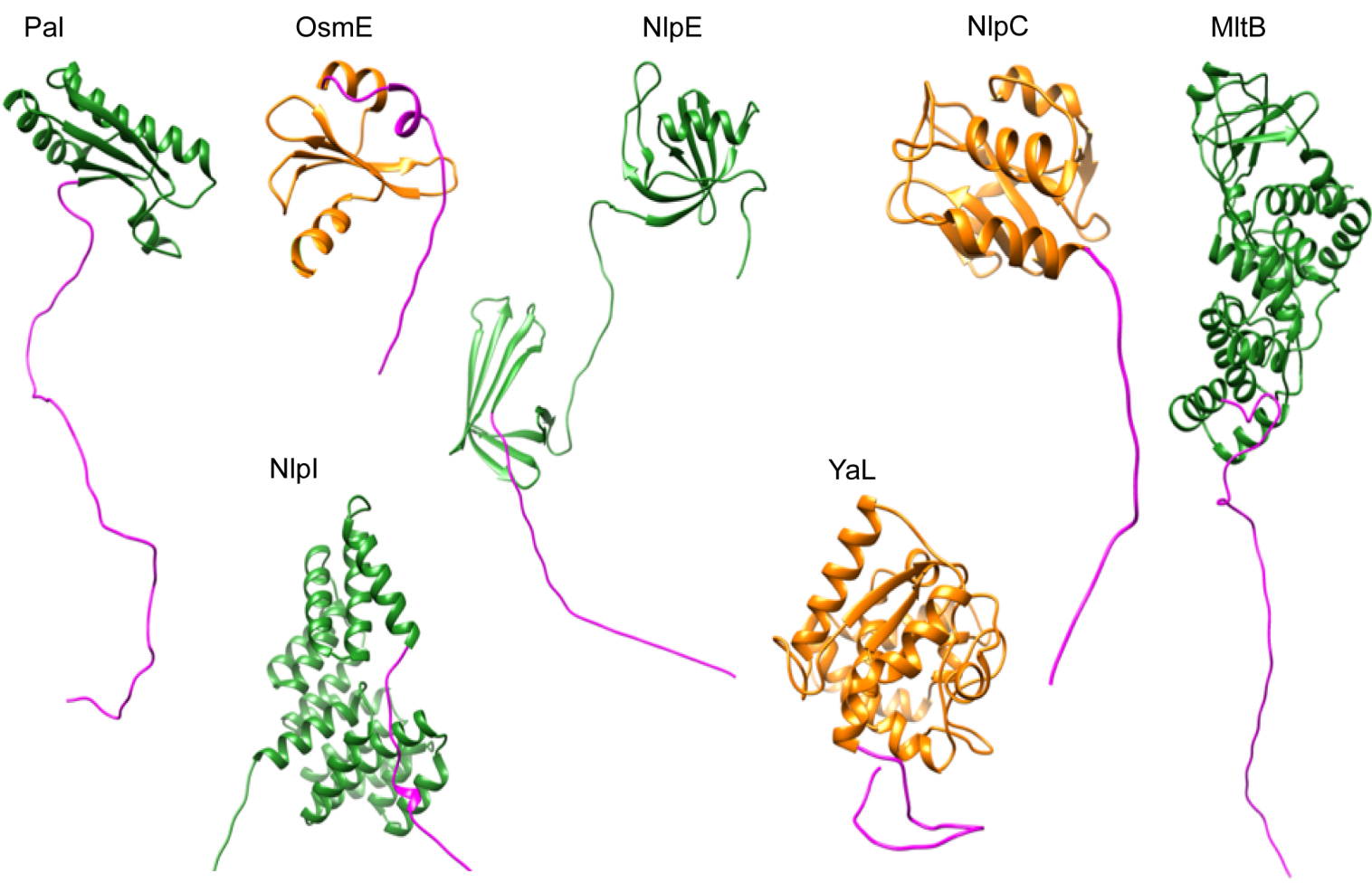

$$
\text { RcsF }
$$

Yajl
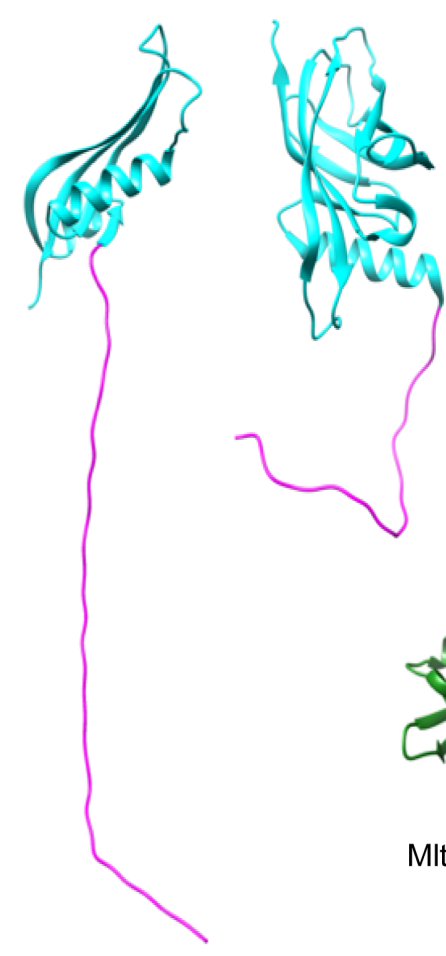

YcfL

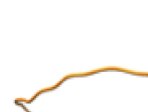

YbaY

RIp

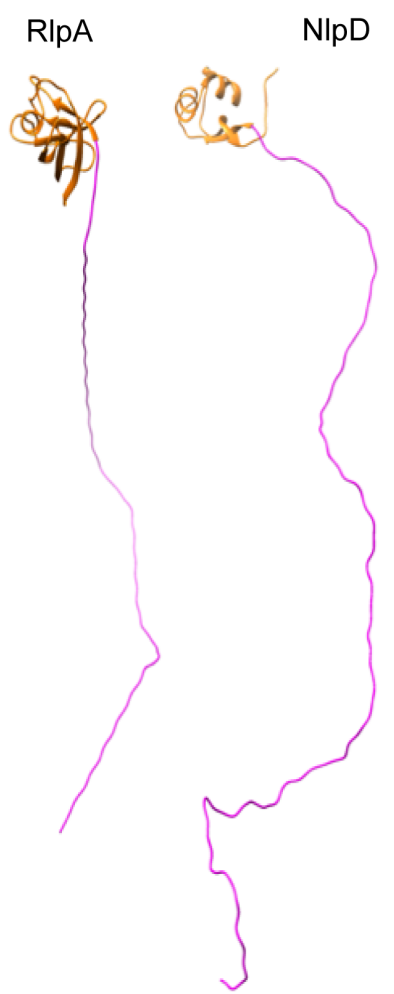


bioRxiv preprint doi: https://doi.org/10.1101/2021.01.05.425367; this version posted January 5, 2021. The copyright holder for this preprint (which was not certified by peer review) is the author/funder, who has granted bioRxiv a license to display the preprint in perpetuity. It is made available under aCC-BY-NC-ND 4.0 International license.

552 Figure 2
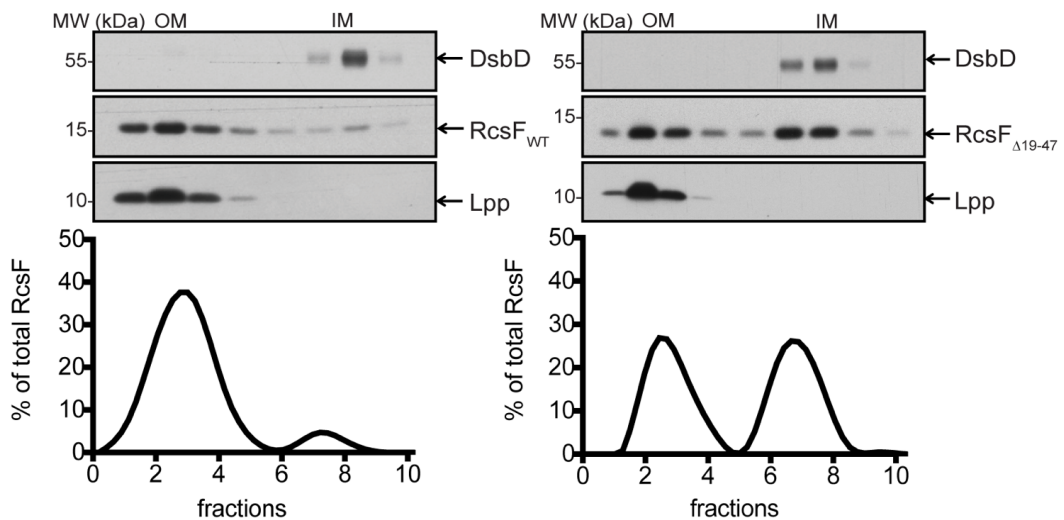

b
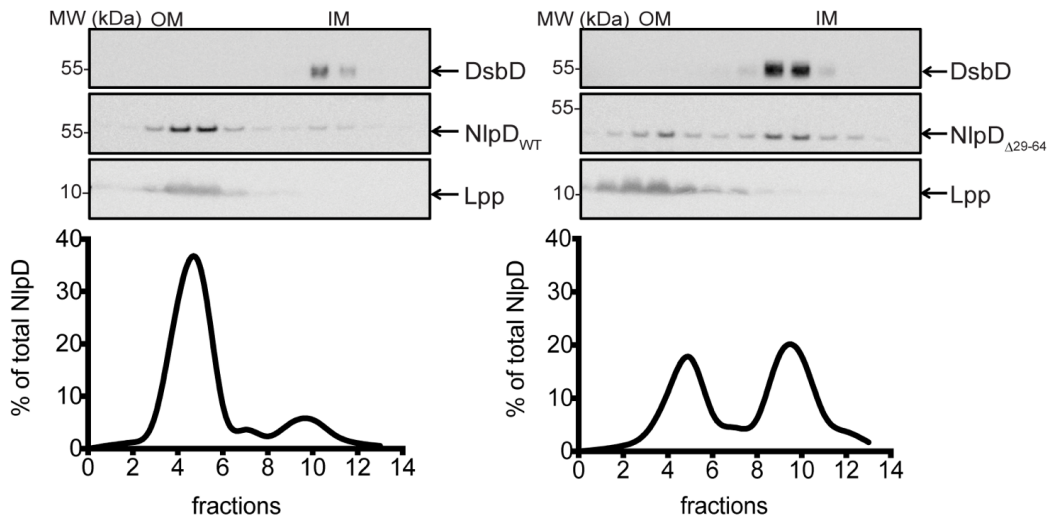

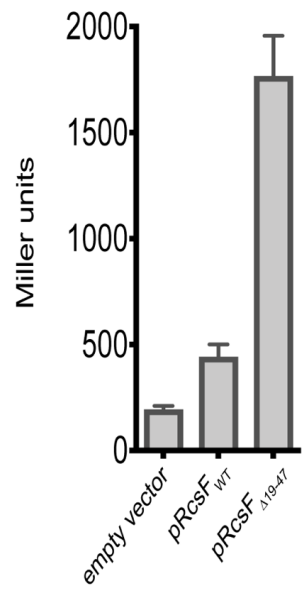

envC.:kan $\triangle n l p D$

envC::kan $\triangle n i p D$ $\mathrm{pNIpD}_{\mathrm{wr}}$
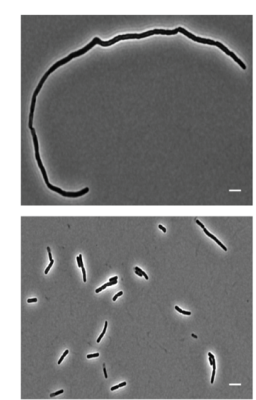

envC::kan $\Delta n I p D$ $\mathrm{pNIpD}_{\Delta 29.64}$

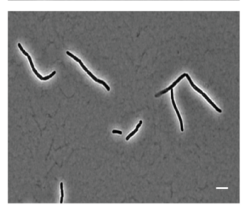

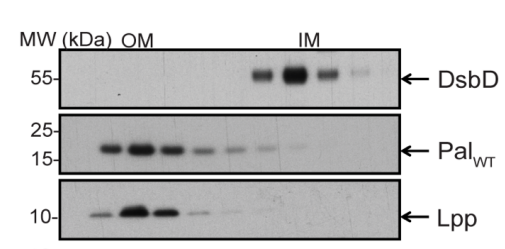
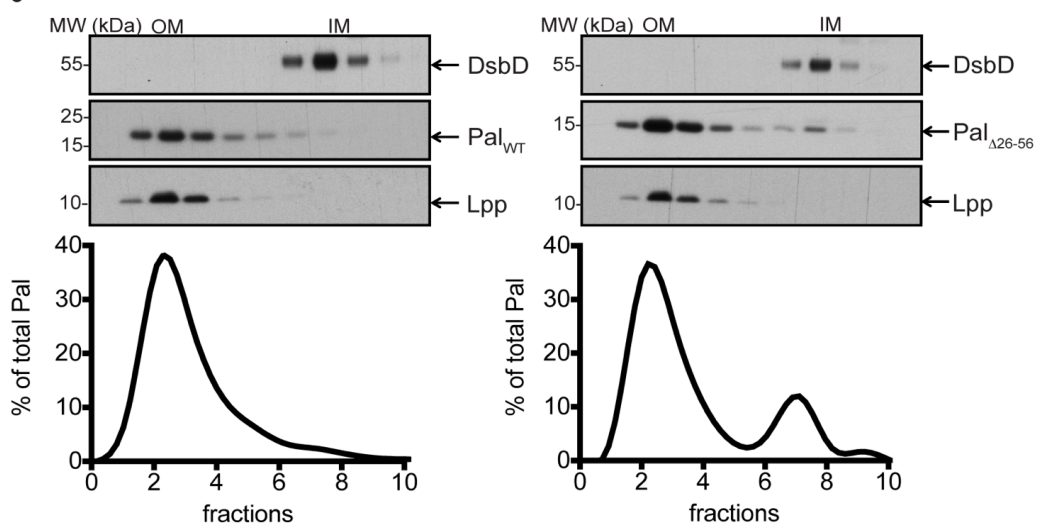

f

LB $37^{\circ} \mathrm{C}$

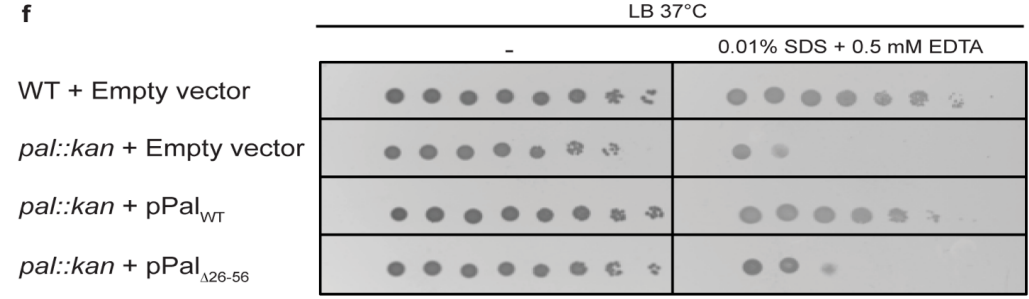


bioRxiv preprint doi: https://doi.org/10.1101/2021 01 05.425367; this version posted January 5, 2021. The copyright holder for this preprint (which was not certified by peer review) is the author/funder, who has granted bioRxiv a license to display the preprint in perpetuity. It is made available under aCC-BY-NC-ND 4.0 International license.

Figure 3

a
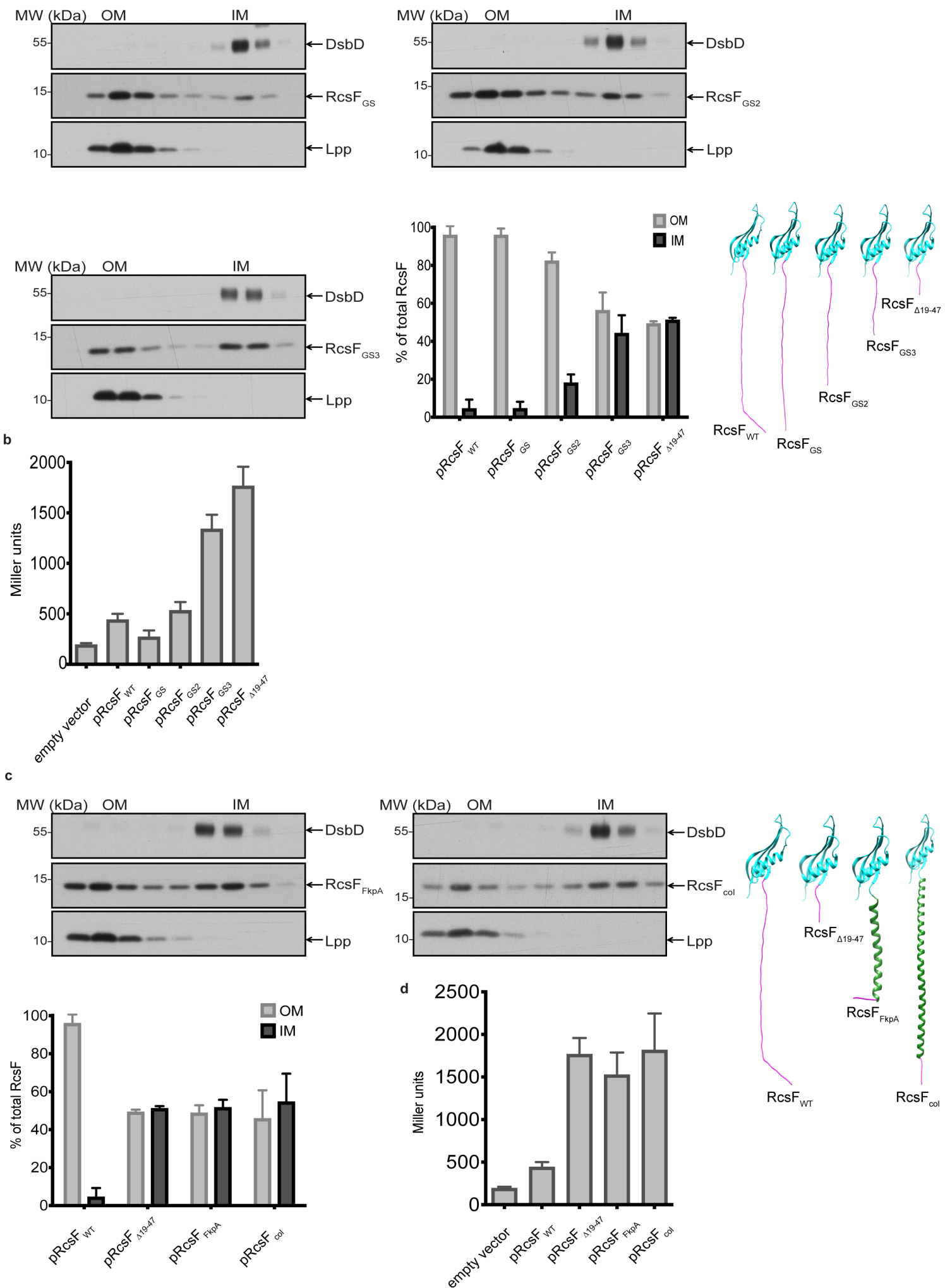
bioRxiv preprint doi: https://doi.org/10.1101/2021.01 05.425367; this version posted January 5, 2021. The copyright holder for this preprint (which was not certified by peer review) is the author/funder, who has granted bioRxiv a license to display the preprint in perpetuity. It is made available under aCC-BY-NC-ND 4.0 International license.

Figure 4

a

Outer membrane

口 Inner membrane

Outer membrane
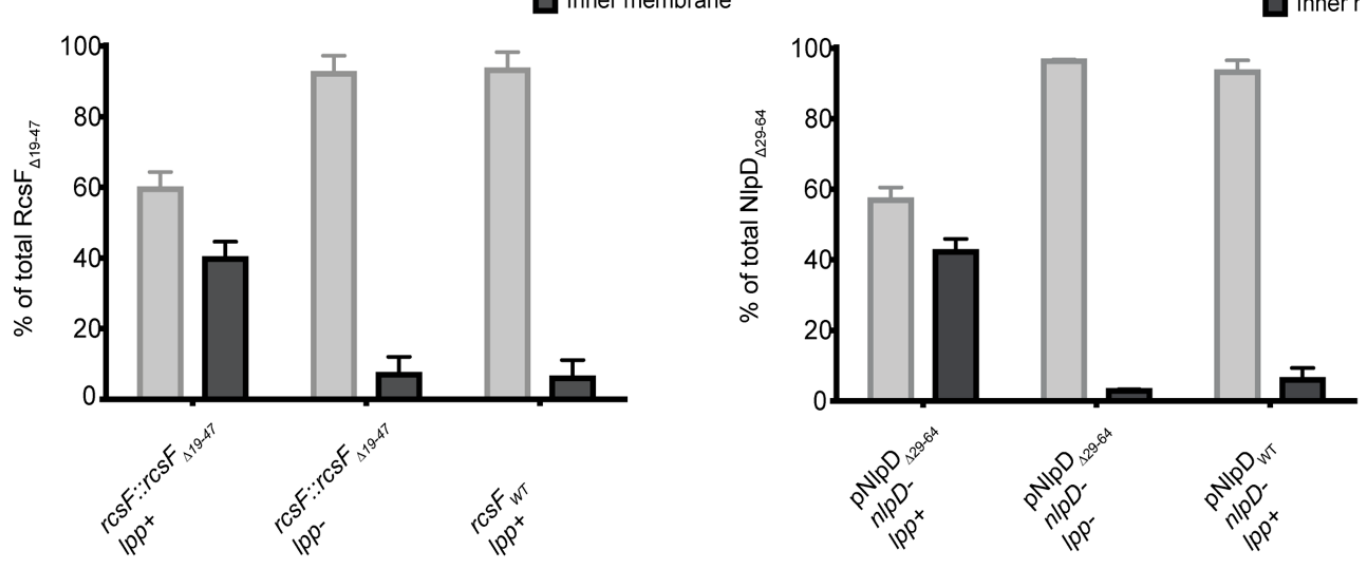

b
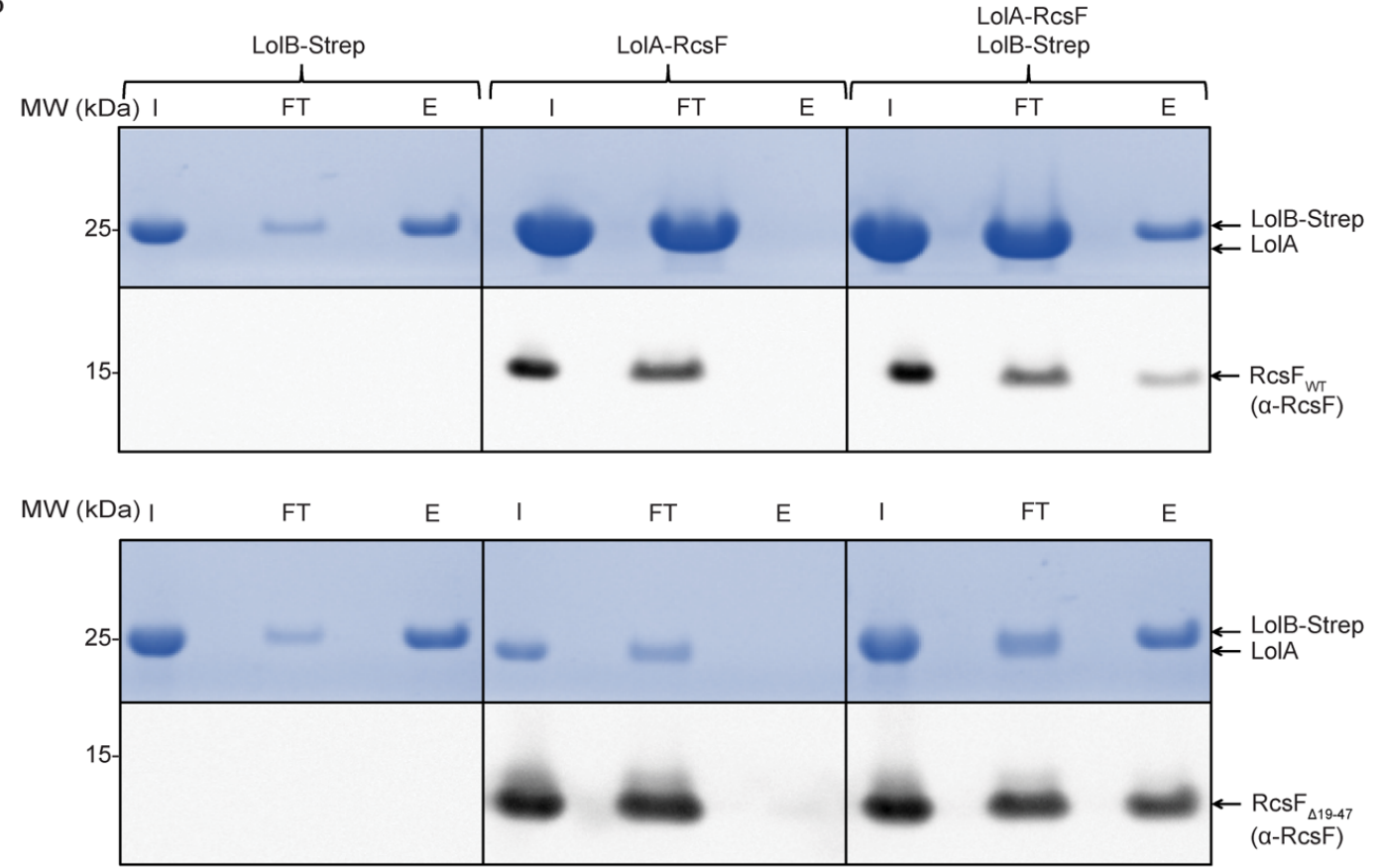
METHODS

\section{Bacterial growth conditions}

571 Bacterial strains used in this study are listed in Extended Data Table 3. Bacterial cells were

572 cultured in Luria broth (LB) at $37{ }^{\circ} \mathrm{C}$ unless stated otherwise. The following antibiotics were

573 added when appropriate: spectinomycin $(100 \mu \mathrm{g} / \mathrm{mL})$, ampicillin $(200 \mu \mathrm{g} / \mathrm{mL})$,

574 chloramphenicol $(25 \mu \mathrm{g} / \mathrm{mL})$, and kanamycin $(50 \mu \mathrm{g} / \mathrm{mL})$. L-arabinose $(0.2 \%)$ and isopropyl-

$575 \beta$-D-thiogalactoside (IPTG) were used for induction when appropriate.

\section{Bacterial strains and plasmids}

578 DH300 (a derivative of Escherichia coli MG1655 carrying a chromosomal rprA::lacZ fusion at

579 the $\lambda$ attachment site $^{47}$ ) was used as wildtype throughout the study. All deletion mutants were

580 obtained by transferring the corresponding alleles from the Keio collection ${ }^{48}\left(\operatorname{kan}^{\mathrm{R}}\right)$ into

$581 \mathrm{DH} 300^{47}$ via P1 phage transduction. Deletions were verified by PCR and the absence of the

582 protein was verified via immunoblotting (when possible). If necessary, the kanamycin cassette

583 was removed via site-specific recombination mediated by the yeast Flp recombinase with pCP20 vector ${ }^{49}$. All strains expressing the RcsF mutants used for subcellular fractionation lacked $\operatorname{rcs} B$ in order to prevent induction of Rcs.

587 The plasmids used in this study are listed in Extended Data Table 4 and the primers appear in

588 Extended Data Table 5. RcsF, Pal, and NlpD were expressed from the low-copy vector pAM $238^{50}$ containing the SC101 origin of replication and the lac promoter. To produce pSC202

590 for RcsF expression, $r c s F$ (including approximately 30 base pairs upstream of the coding 591 sequence) was amplified by PCR from the chromosome of DH300 (primer pair SH_RcsF(PstI)- 
592 R and SH_RcsFU-R (kpnI)-F). The amplification product was digested with KpnI and PstI and 593 inserted into pAM238, resulting in pSC202. nlpD was amplified using primers JR1 and JR2 594 and pal was amplified with primers JS145 and JS146. Amplification products were digested 595 with PstI-XbaI and KpnI-XbaI, respectively, generating pJR8 (for NlpD expression) and pJS20 596 (for Pal expression). To clone $r \operatorname{cs} F_{\Delta 19-47}$, the nucleotides encoding the RcsF signal sequence 597 were amplified using primers SH_RcsFUR(kpnI)_F and SH_RcsFss-Fsg (NcoI)_R, and those 598 encoding the RcsF signaling domain were amplified using primers SH_RcsFss-Fsg (NcoI)_R and SH_RcsF(PstI)_R. In both cases, pSC202 was used as template. Then, overlapping PCR was performed using SH_RcsFUR(kpnI)_F and SH_RcsF(PstI)_R from the two PCR products 601 previously obtained. The final product was digested with KpnI and PstI, and ligated with 602 pAM238 pre-digested with the same enzymes, yielding pSC201. To add a GS linker (Ser-GlySer-Gly-Ser-Gly-Ala-Met) into pSC201, the primers SH_GS linker_F and SH_GS linker_R were mixed, boiled, annealed at room temperature, and ligated with pSC201 pre-digested with NcoI, generating pSC198.pSC199 was generated similarly, but using primers SH_SG linker_F and SH_SG linker_R and plasmid pSC198. pSC200 was generated using primers SH_Da 607 linker_F and SH_SG linker_R and plasmid pSC199. The pal allele lacking the linker region 608 (pal $\left.{ }_{\Delta 26-56}\right)$ was created via overlapping PCR. The pJS20 plasmid served as template for PCR with the M13R/M13F external primers and JS152/JS153 internal primers. The truncated allele

610 was cloned into pAM238 at the same restriction sites as the full-length allele, producing pJS24.

611 The $n l p D$ allele lacking the linker regions $\left(n l p D_{429-64}\right)$ was created via overlapping PCR. E. coli 612 chromosomal $n l p D$ served as template for the PCR, with JR1/JR2 as external primers and 613 JR7/JR8 as internal primers. The truncated allele was then cloned into pAM238 at the same 614 restriction sites as the full-length allele, producing pJR10. 
$616 r c s F_{F k p A}$ and $r c s F_{c o l}$ were obtained by inserting DNA sequences corresponding to helical linker 617 fragments (FkpA Ser94-Glu125 and colicin IA Ile213-Lys282) into $r c s F_{\Delta 19-47}$ at NcoI and RsrII

618 restriction sites. The $f k p A$ gene fragment was amplified from the E. coli MC4100 chromosome

619 (JS50/JS51 primers) and the cia gene fragment was chemically synthetized as a gene block by 620 Integrated DNA Technologies (IDT). The resulting plasmids were pJS18 and pJS27, 621 respectively. pAM238 does not contain the lacIq repressor. Therefore, to enable expression622 level regulation by IPTG, strains containing the pAM238 plasmids expressing RcsF variants were co-transformed with pET22b, a high-copy plasmid from a different incompatibility group (pBR223 origin of replication; Novagen) containing the lacIq repressor. Chromosomal insertion of $\mathrm{RcsF}_{\Delta 19-47}$ was performed via $\lambda$-Red recombineering ${ }^{51}$ with pSIM5-Tet plasmid (a 626 gift of D. Hughes). In the first step, the cat-sacB cassette was introduced and later replaced by mutant $\operatorname{rcs} F$.

The chromosomal lolCDE operon was amplified via PCR using primers JS277 and JS278 630 (adding a C-terminal His-tag to LolE) and then inserted into pBAD33 using the restriction sites 631 PstI and XbaI, resulting in pJR203. The expression level of LolE-His was verified via immunoblotting.

634 The sequence encoding lolB without its N-terminal cysteine was first amplified from the 635 chromosome via PCR using primers JR50/PL387 (adding a C-terminal Strep-tag). It was then 636 cloned into pET28a using the restriction sites XbaI and PstI. lolA was amplified using 637 chromosomal lolA as PCR template for primers JR30/JR31 (JR31 contains the sequence of a 638 His-tag) and then cloned into pBAD18 using KpnI and XbaI, resulting in pJR48. 
640 The genes encoding Lgt and Lnt were amplified from the chromosome with PCR primers

641 AG389/AG403 and AG393/JR74, respectively. AG403 and JR74 also encode a Myc-tag. PCR

642 products were cloned into pAM238 using KpnI and PstI. Expression levels were verified via

643 immunoblotting (data not shown). lspA was amplified with PCR primers JR77/JR78. The PCR

644 product was cloned into pSC213, a modified pAM238 with a ribosome binding site and a C-

645 terminal Flag tag, using NcoI and BamHI. Expression of LspA-Flag was induced by adding 25

$646 \mu \mathrm{M}$ IPTG. Expression levels were verified with immunoblots (data not shown).

647

\section{Cell fractionation and sucrose density gradients}

649 Cell fractionation was performed as described previously ${ }^{52}$ with some modifications. Four

650 hundred milliliters of cells were grown until the optical density at $600 \mathrm{~nm}\left(\mathrm{OD}_{600}\right)$ of the culture reached 0.7. Cells were harvested via centrifugation at $6,000 \mathrm{x} g$ at $4{ }^{\circ} \mathrm{C}$ for $15 \mathrm{~min}$, washed

buffer. The washing step was skipped with the $\Delta l p p$ strains to prevent the loss of outer membrane vesicles. DNase I (1 mg; Roche), $1 \mathrm{mg}$ RNase A (Thermo Scientific), and a half tablet of a protease inhibitor cocktail (cOmplete EDTA-free Protease Inhibitor Cocktail tablets; $5,000 \mathrm{x} g$ at $4{ }^{\circ} \mathrm{C}$ for $15 \mathrm{~min}$ in order to remove cell debris. Then, $16 \mathrm{~mL}$ of supernatant were

659 placed on top of a two-step sucrose gradient (2.3 $\mathrm{mL}$ of $2.02 \mathrm{M}$ sucrose in $10 \mathrm{mM}$ HEPES pH and the membrane fraction were collected. The membrane fraction was diluted four times with $10 \mathrm{mM}$ HEPES $\mathrm{pH}$ 7.5. To separate the inner and the outer membranes, $7 \mathrm{~mL}$ of the diluted membrane fraction were loaded on top of a second sucrose gradient $(10.5 \mathrm{~mL}$ of $2.02 \mathrm{M}$ sucrose, 
$66512.5 \mathrm{~mL}$ of $1.44 \mathrm{M}$ sucrose, $7 \mathrm{~mL}$ of $0.77 \mathrm{M}$ sucrose, always in $10 \mathrm{mM}$ HEPES $\mathrm{pH}$ 7.5). The

666

667

668

669

670

671

672

673

674

675

676

677

678

679

680

681

682

683

684

685

686

687

688

689 samples were then centrifuged at $112,000 \mathrm{x} g$ for $16 \mathrm{~h}$ at $10{ }^{\circ} \mathrm{C}$ in a SW 28 Beckman rotor. Approximately 30 fractions of $1.5 \mathrm{~mL}$ were collected and odd-numbered fractions were subjected to SDS-PAGE, transferred onto a nitrocellulose membrane, and probed with specific antibodies. Graphs were created in GraphPad Prism 9 via spline analysis of the curves representing a mean of three independent experiments.

\section{Immunoblotting}

Protein samples were separated via $10 \%$ or $4-12 \%$ SDS-PAGE (Life Technologies) and transferred onto nitrocellulose membranes (GE Healthcare Life Sciences). The membranes were blocked with 5\% skim milk in $50 \mathrm{mM}$ Tris- $\mathrm{HCl} \mathrm{pH} 7.6,0.15 \mathrm{M} \mathrm{NaCl}$, and $0.1 \%$ Tween 20 (TBS-T). TBS-T was used in all subsequent immunoblotting steps. The primary antibodies were diluted 5,000 to 20,000 times in $1 \%$ skim milk in TBS-T and incubated with the membrane for $1 \mathrm{~h}$ at room temperature. The anti-RcsF, anti-DsbD, anti-Lpp, anti-NlpD, anti-LolA, and anti-LolB antisera were generated by our lab. Anti-Pal was a gift from R. Lloubès, and anti-His is a peroxidase-conjugated antibody (Qiagen). The membranes were incubated for $1 \mathrm{~h}$ at room temperature with horseradish peroxidase-conjugated goat anti-rabbit IgG (Sigma) at a 1:10,000 dilution. Labelled proteins were detected via enhanced chemiluminescence (Pierce ECL Western Blotting Substrate, Thermo Scientific) and visualized using X-ray film (Fuji) or a camera (Image Quant LAS 4000 and Vilber Fusion solo S). In order to quantify proteins levels, band intensities were measured using ImageJ version 1.46r (National Institutes of Health).

\section{$\beta$-galactosidase assay}

$\beta$-galactosidase activity was measured as described previously ${ }^{53}$. Graphs representing a mean of six experiments with standard deviation were prepared in GraphPad Prism. Expression-level 
690 estimations were performed as follows. Cultures used for $\beta$-galactosidase activity $(0.5 \mathrm{~mL}$ per

691 culture) were precipitated with 10\% trichloroacetic acid, washed with ice-cold acetone, and

692 resuspended in $0.2 \mathrm{~mL}$ Laemmli SDS sample buffer. Samples ( $5 \mu \mathrm{L})$ were subjected to SDS-

693 PAGE and immunoblotted with anti-RcsF antibody.

694

695 SDS-EDTA sensitivity assay

696 Cells were grown in $\mathrm{LB}$ at $37^{\circ} \mathrm{C}$ until they reached an $\mathrm{OD}_{600}$ of 0.7 . Tenfold serial dilutions

697 were made in LB and plated on LB agar supplemented with spectinomycin $(100 \mu \mathrm{g} / \mathrm{mL})$ when

698 necessary. Plates were incubated at $37^{\circ} \mathrm{C}$. To evaluate the sensitivity of the pal mutant, plates

699 were supplemented with $0.01 \%$ SDS and $0.5 \mathrm{mM}$ EDTA.

700

701

\section{Microscopy image acquisition}

702 Cells were grown in $\mathrm{LB}$ at $37^{\circ} \mathrm{C}$ until $\mathrm{OD}_{600}=0.5$. Cells growing in exponential phase were spotted onto a $1 \%$ agarose phosphate-buffered saline pad for imaging. Cells were imaged on a Nikon Eclipse Ti2-E inverted fluorescence microscope with a CFI Plan Apochromat DM $25 \mathrm{~mm}$ camera (Photometrics). We used a Cy5-4050C (32 mm) filter cube (Nikon). Image acquisition was performed with NIS-Element Advance Research version 4.5.

\section{Protein purification}

710 JR90 cells were grown in LB supplemented with kanamycin $(50 \mu \mathrm{g} / \mathrm{mL})$ at $37^{\circ} \mathrm{C}$. When the

711 culture $\mathrm{OD}_{600}=0.5$, the expression of cytoplasmic LolB-Strep was induced with $1 \mathrm{mM}$ IPTG.

712 Cells $(1 \mathrm{~L})$ were pelleted when they reached $\mathrm{OD}_{600}=3$ and resuspended in $25 \mathrm{~mL}$ of buffer $\mathrm{A}$

$713(200 \mathrm{mM} \mathrm{NaCl}$ and $50 \mathrm{mM} \mathrm{NaPi}, \mathrm{pH}$ 8) containing one tablet of cOmplete EDTA-free Protease

714 Inhibitor Cocktail (Roche). Cells were lysed via two passages through a French pressure cell at 
$1,500 \mathrm{psi}$. The lysate was centrifuged at $30,000 \mathrm{x} g$ for $40 \mathrm{~min}$ at $4{ }^{\circ} \mathrm{C}$ in a JA 20 rotor and the supernatant was mixed with Strep-Tactin resin (IBA Lifesciences) previously equilibrated with finally desalted using a PD10 column (GE Healthcare).

Soluble LolA-RcsF $\mathrm{WT}_{\mathrm{WT}}$ and $\mathrm{LoA} \mathrm{RcsF}_{\Delta 19-47}$ complexes were purified via affinity

To obtain the soluble fraction, the supernatant was centrifuged at $180,000 \mathrm{xg}$ for $1 \mathrm{~h}$ at $4{ }^{\circ} \mathrm{C}$ using the same rotor. The supernatant was added to a His Trap HP column (Merck) previously equilibrated with buffer A. The column was washed with 10 column volumes of buffer A supplemented with $20 \mathrm{mM}$ imidazole and LolA-His was eluted using a gradient of imidazole

732 (from $20 \mathrm{mM}$ to $300 \mathrm{mM}$ ). The fractions obtained were analyzed via SDS-PAGE; LolA was detected around $25 \mathrm{kDa}$ (data not shown). RcsF variants were detected via immunoblotting with

734 an anti-RcsF antibody. Fractions containing LolA-RcsF variants were pooled, concentrated to

$7351 \mathrm{~mL}$ using a Vivaspin 4 Turbo concentrator (Cut-off $5 \mathrm{kDa}$; Sartorius), and purified via sizeexclusion chromatography with a Superdex S75-10/300 column (GE Healthcare). 
739 LolB-Strep was incubated at $30^{\circ} \mathrm{C}$ for 20 min under agitation with LolA-RcsF wT or with LolA-

$740 \mathrm{RcsF}_{\Delta 19-47}\left(\mathrm{LolA}-\mathrm{RcsF}_{\mathrm{WT}}\right.$ and LolA-RcsF $\mathrm{R}_{\Delta 19-47}$ complexes were purified as described above).

741 The mixture was added to magnetic Strep beads (MagStrep type 3 beads, IBA Life science)

742 previously equilibrated with buffer $\mathrm{A}$ and incubated for 30 min at $4{ }^{\circ} \mathrm{C}$ on a roller. After washing

743 the beads with the same buffer, LolB-Strep was eluted with buffer A supplemented with $50 \mathrm{mM}$

744 biotin. Samples were analyzed via SDS-PAGE and LolA and LolB were detected with

745 Coomassie Brilliant Blue (Bio-Rad). RcsF was detected via immunoblotting with an anti-RcsF

746 antibody.

747

748 Structural analysis of lipoproteins

749 When X-ray, cryo-EM, or NMR structures were available, the missing residues were completed

750 through comparative modeling using MODELLER version $9.22^{54}$. If no structure of the

751 lipoprotein was available, then the most pertinent analogous structure from proteins belonging

752 to the same PFAM group was used as template for comparative modeling. The linker was

753 defined as the unstructured fragment from the N-terminal Cys of the mature form until the first

754 residue with well-defined secondary structure ( $\alpha$-helix or $\beta$-strand) belonging to a globular

755 domain. Short, intermediate, and long linkers had lengths of $<12,12-22$, and $>22$ residues,

756 respectively. Images were generated using UCSF Chimera version $1.13 .1^{55}$. 


\section{LEGENDS FOR FIGURES IN THE EXTENDED DATA}

Extended Data Figure 1. Lipoprotein maturation and sorting in the $E$. coli cell envelope. the residues at position +2 and +3 . LolCDE transfers the lipoprotein to the periplasmic chaperone LolA (step 5), which delivers the lipoprotein to LolB (step 6). LolB, a lipoprotein itself, inserts the lipoprotein in the outer membrane using a poorly understood mechanism (step

7). b. Schematic of lipoprotein structural domains. The N-terminal signal sequence targets the lipoprotein to the cell envelope; the last four amino acid residues of the signal sequence form the lipobox. The last residue of the lipobox is the invariant cysteine that undergoes lipidation. This cysteine, which is the first residue of the mature lipoprotein, is directly followed by the sorting signal, a sequence of 2 or 3 amino acids that controls the sorting of mature lipoproteins between the inner and outer membranes. The C-terminal portion of a mature lipoprotein is a globular domain. An intrinsically disordered linker separates the sorting signal from the globular domain in about half of E. coli lipoproteins (Fig. 1; Extended Data Fig. 2; Extended

Data Table 1). The lengths of the deleted disordered linkers of the unrelated lipoproteins RcsF, Pal, and NlpD are indicated. LP, lipoprotein. membrane lipoproteins display an intrinsically disordered linker at the $\mathbf{N}$-terminus.

779 Structures were generated via comparative modeling. X-ray and cryo-EM structures are green, 780 NMR structures are cyan, and structures built via comparative modeling from the closest analog 781 in the same PFAM group are orange. In all cases, the N-terminal linker is magenta. Lipoproteins 782 targeting the outer membrane: AmiD, BamB, BamC, HslJ, MltA, LoiP, LpoB, Blc, BamE, 783 CsgG, EmtA, GfcE, BamD, LpoA, LolB, LptE, MlaA, MliC, YddW, YedD, YghG, YfeY, 
784 YbjP, YiaD, YbhC, PqiC, YgeR, YfiB, YraP. Lipoproteins targeting the IM: DcrB, MetQ,

785 NlpA, YcjN, YehR, ApbE. Synthetic constructs: RcsF ${ }_{\mathrm{GS}}, \mathrm{RcsF}_{\mathrm{GS} 2}, \mathrm{RcsF}_{\mathrm{GS} 3}, \mathrm{RcsF}_{\Delta 19-47}$,

$\mathrm{RcsF}_{\mathrm{FkpA}}, \mathrm{RcsF}_{\mathrm{col}}, \mathrm{NlpD}_{\Delta 29-64}, \mathrm{Pal}_{\Delta 26-56}$.

787

Extended Data Figure 3. Expression levels of $\operatorname{ResF}_{\Delta 19-47}$, Pal $_{\Delta 26-56}$, and NIpD $_{\Delta 29-64}$.

789 Cells were grown at $37^{\circ} \mathrm{C}$ in $\mathrm{LB}$ until $\mathrm{OD}_{600}=0.5$ and precipitated with trichloroacetic acid

790 (Methods). Immunoblots were performed with $\alpha$-RcsF, $\alpha-\mathrm{NlpD}$, and $\alpha$-Pal antibodies

791 (Methods). All images are representative of three independent experiments.

792

793 Extended Data Figure 4. Schematic of ResF variants used in this study and their

distributions in the outer membrane (OM) and inner membrane (IM).

795

$\mathrm{RcsF}_{\mathrm{GS}}, \mathrm{RcsF}_{\mathrm{GS} 2}$, and $\mathrm{RcsF}_{\mathrm{GS} 3}$ have linkers that are disordered and mostly consist of GS repeats.

The linker of $\mathrm{RcsF}_{\mathrm{GS}}$ is the same length as the linker of $\mathrm{RcsF}_{\mathrm{WT}}$. $\mathrm{RcsF}_{\mathrm{GS} 2}$ and $\mathrm{RcsF}_{\mathrm{GS} 3}$ are shorter

than $\mathrm{RcsF}_{\mathrm{WT}}$. Regions of $\mathrm{RcsF}_{\mathrm{FkpA}}$ and $\mathrm{RcsF}_{\mathrm{col}}$ fold into alpha helices borrowed from the sequences of FkpA and colicin Ia, respectively.

799

Extended Data Figure 5. Complexes between LolA and $\operatorname{ResF}_{W T}$ or $\operatorname{ResF}_{\Delta 19-47}$ can be purified.

802 Both $\operatorname{RcsF}_{\mathrm{WT}}$ (a) and $\mathrm{RcsF}_{\Delta 19-47}$ (b) were eluted in complex with LolA-His via affinity

803 chromatography followed by size exclusion chromatography. Gel filtration was performed with 804 a Superdex S75-10/300 column. Samples were analyzed via SDS-PAGE and proteins, 805 including LolA-His, were stained with Coomassie Brilliant Blue (Methods). RcsF variants were 806 detected by immunoblotting fractions with $\alpha-R \operatorname{csF}$ antibodies. Images are representative of 807 three independent experiments. 
809 Extended Data Figure 6. Overexpression of Lol CDE does not restore targeting of ResF $F_{\Delta 19-}$

$810 \quad 47$.

811 a. Expression level of LolCDE-His. Cells were grown in LB plus $0.2 \%$ arabinose at $37^{\circ} \mathrm{C}$ until

$812 \mathrm{OD}_{600}=0.7$ (Methods). Membrane and soluble fractions were separated with a sucrose density

813 gradient (Methods). LolE-His was detected in the membrane fraction by immunoblotting with

$814 \alpha$-His (Methods). Images are representative of three independent experiments. b. The outer

815 membrane (OM) and inner membrane (IM) were separated with a sucrose density gradient.

816 Expression of LolCDE did not rescue $\mathrm{OM}$ targeting of $\mathrm{RcsF}_{\Delta 19-47}$. Images are representative of

817 experiments performed in biological triplicate.

818

819 Extended Data Figure 7. Overexpressing Lgt, LspA, and Lnt does not rescue the targeting

820 of $\operatorname{ResF}_{\Delta 19-47}$ to the outer membrane.

821 a. Expression levels of Lgt, LspA, and Lnt. Cells were grown in LB (plus $25 \mu \mathrm{M}$ IPTG for cells

822 expressing LspA) at $37{ }^{\circ} \mathrm{C}$ until $\mathrm{OD}_{600}=0.7$ (Methods). Outer membrane (OM) and inner

823 membrane (IM) were separated with a sucrose density gradient (Methods). Lgt-Myc and Lnt-

824 Myc were detected in the IM via immunoblotting with $\alpha$-Myc. LspA-Flag was detected in the

825 IM with $\alpha$-Flag. b. Cells overexpressing Lgt, LspA, or Lnt were exposed to a sucrose density

826 gradient (Methods). $\mathrm{RcsF}_{\Delta 19-47}$ was retained in the IM in all conditions. Images are

827 representative of three independent experiments.

828 
bioRxiv preprint doi: https://doi.org/10.1101/2021.01 05.425367; this version posted January 5, 2021. The copyright holder for this preprint (which was not certified by peer review) is the author/funder, who has granted bioRxiv a license to display the preprint in perpetuity. It is made available under aCC-BY-NC-ND 4.0 International license.

a

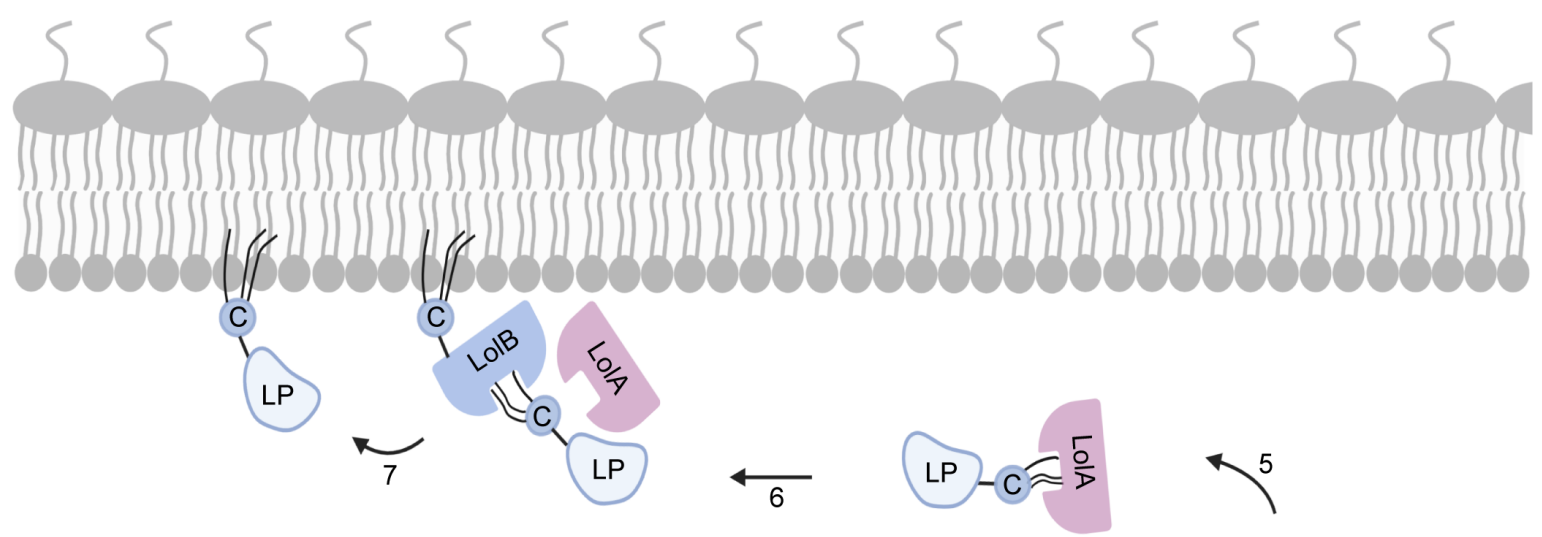

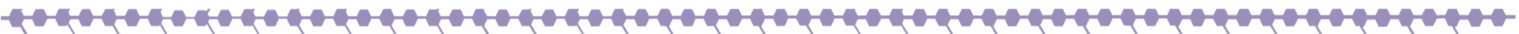

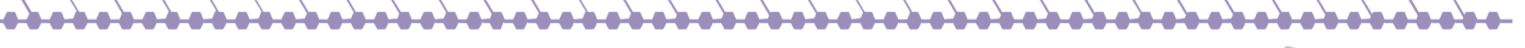

Periplasm

LOIA

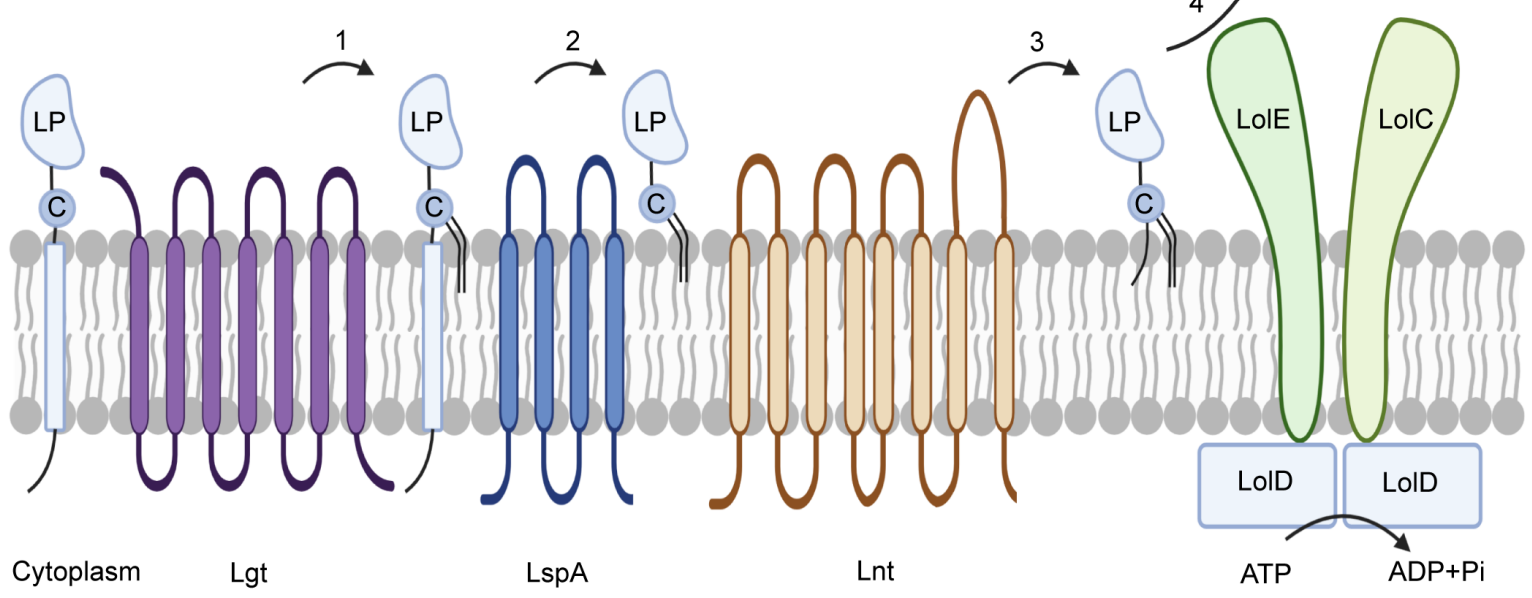

b

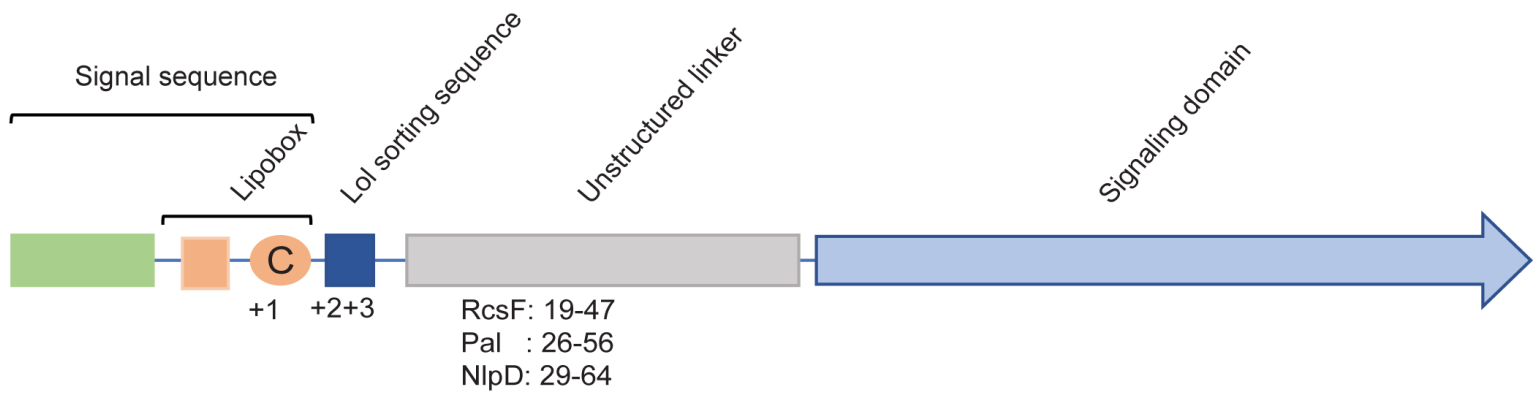


bioRxiv preprint doi https://doi. org/10.1101/2021.01.05 425367: this version posted January 5, 2021. The copyright holder for this preprint

\section{Extended Data Figure 2}

\section{Lipoproteins targeting the outer membrane}



Lipoproteins targeting the inner membrane



\section{Extended Data Figure 3}

838
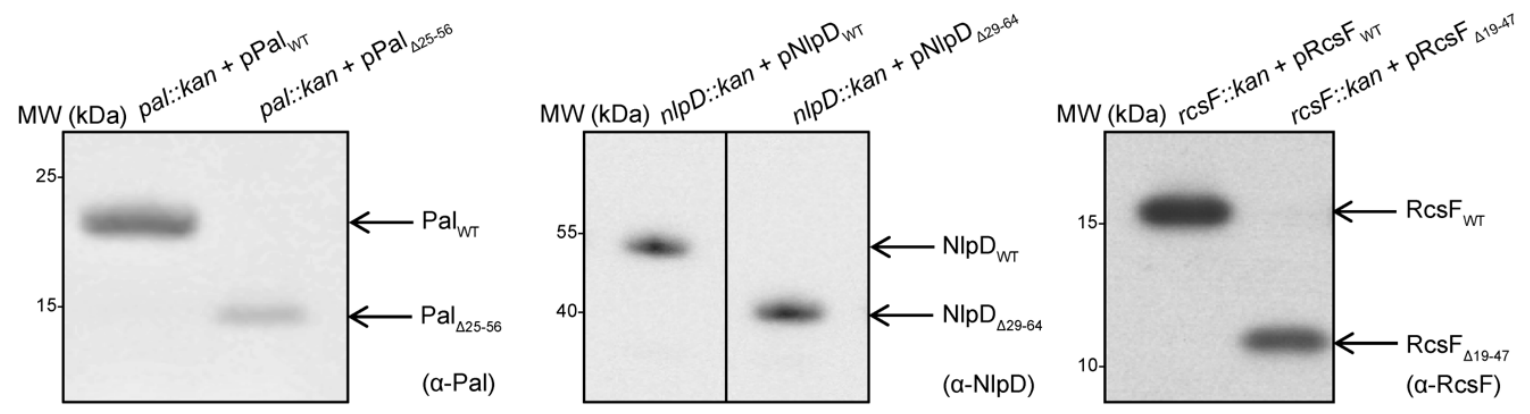

839 
bioRxiv preprint doi: https://doi.org/10.1101/2021.01 05.425367; this version posted January 5, 2021. The copyright holder for this preprint (which was not certified by peer review) is the author/funder, who has granted bioRxiv a license to display the preprint in perpetuity. It is made available under aCC-BY-NC-ND 4.0 International license.

\section{Extended Data Figure 4}

841

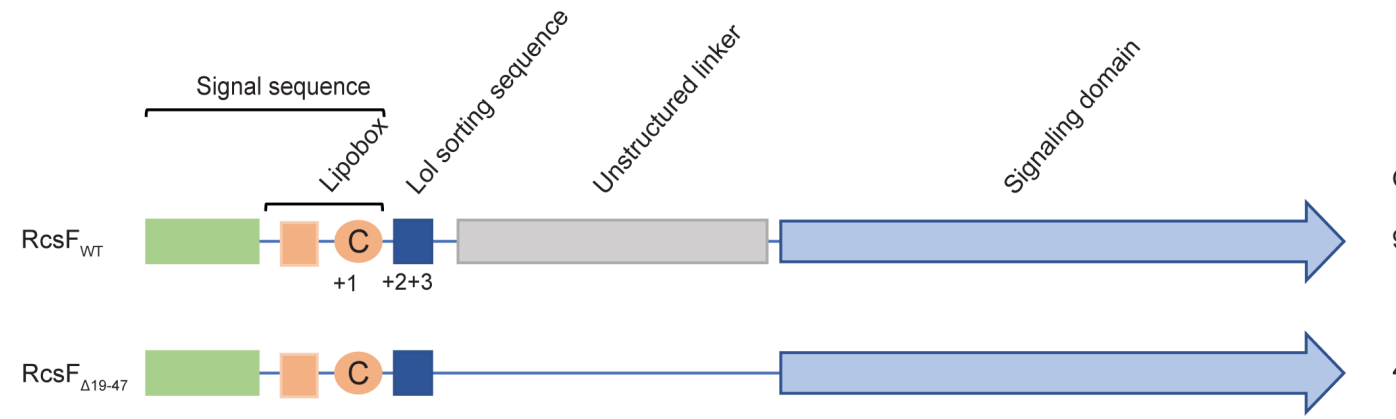

OM IM
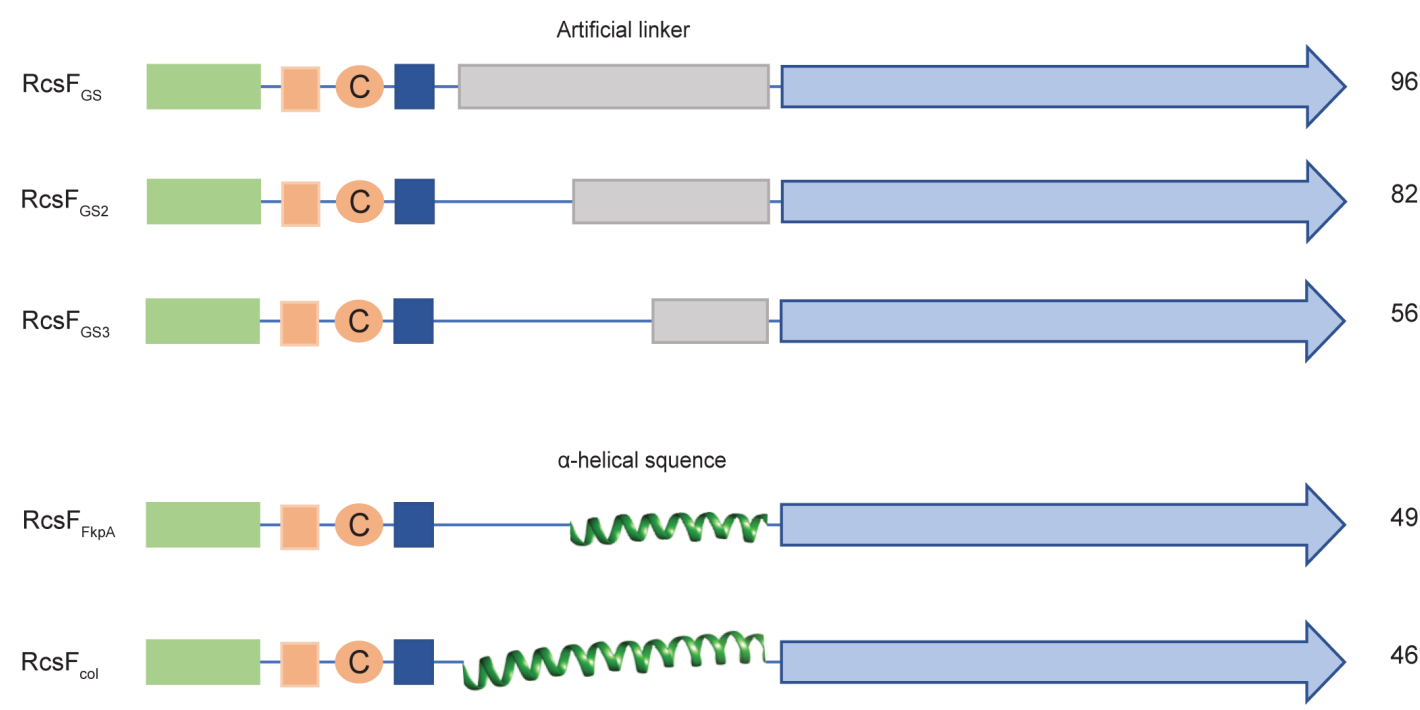
bioRxiv preprint doi: https://doi org/10.1101/2021.01 05.425367; this version posted January 5, 2021. The copyright holder for this preprint (which was not certified by peer review) is the author/funder, who has granted bioRxiv a license to display the preprint in perpetuity. It is made available under aCC-BY-NC-ND 4.0 International license.

Extended Data Figure 5

a
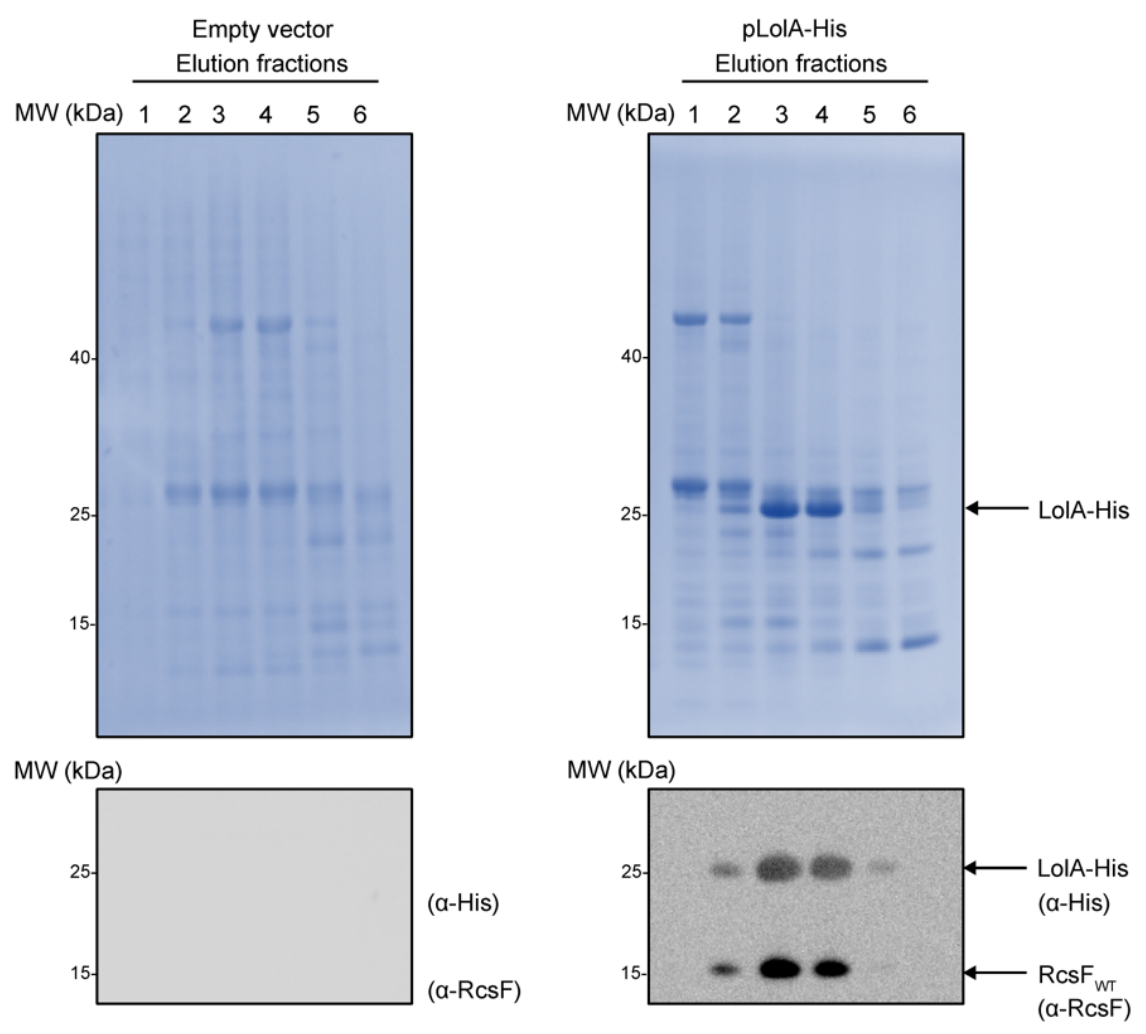

b

$\mathrm{MW}(\mathrm{kDa})$

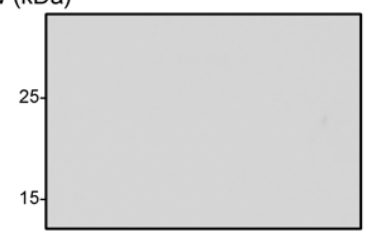

Empty vector Elution fractions

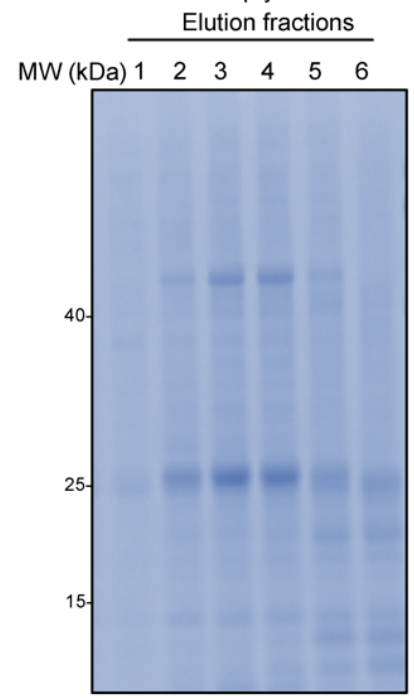

$\mathrm{MW}(\mathrm{kDa})$



pLolA-His

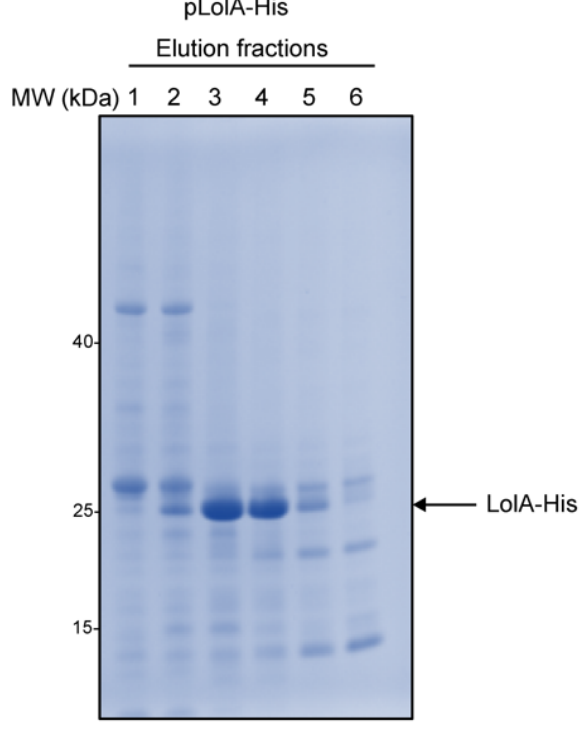

$\mathrm{MW}(\mathrm{kDa})$

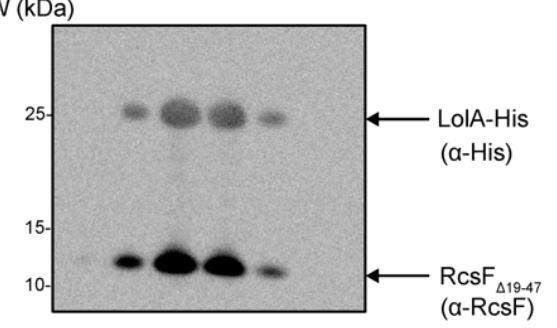


bioRxiv preprint doi: $\mathrm{https}$ //doi.org/10.1101/2021.01.05.425367; this version posted January 5, 2021. The copyright holder for this preprint (which was not certified by peer review) is the author/funder, who has granted bioRxiv a license to display the preprint in perpetuity. It is made available under aCC-BY-NC-ND 4.0 International license.

\section{Extended Data Figure 6}

a

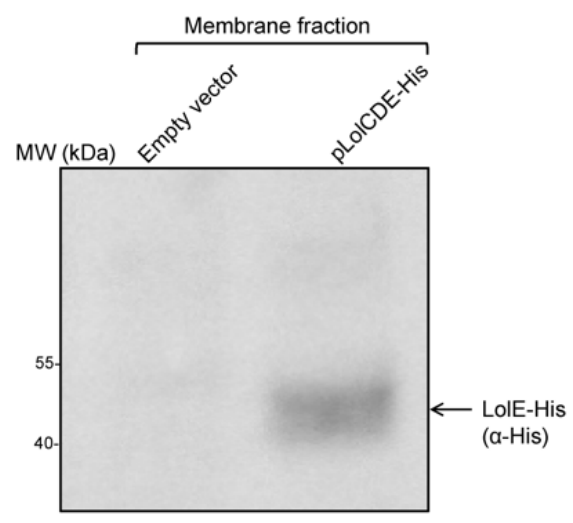

b
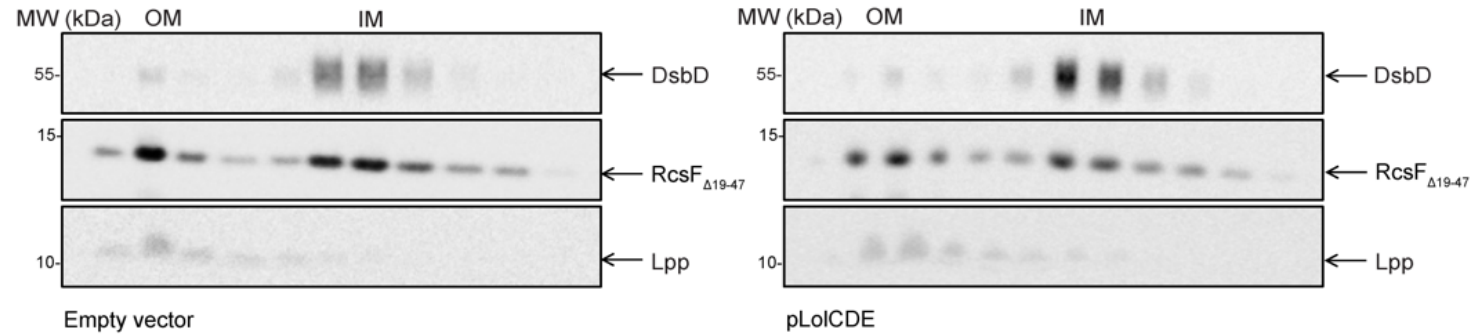

846 
bioRxiv preprint doi: https://doi. org/10.1101/2021.01 05.425367: this version posted January 5, 2021. The copyright holder for this preprint (which was not certified by peer review) is the author/funder, who has granted bioRxiv a license to display the preprint in perpetuity. It is made available under aCC-BY-NC-ND 4.0 International license.

\section{$847 \quad$ Extended Data Figure 7}

a

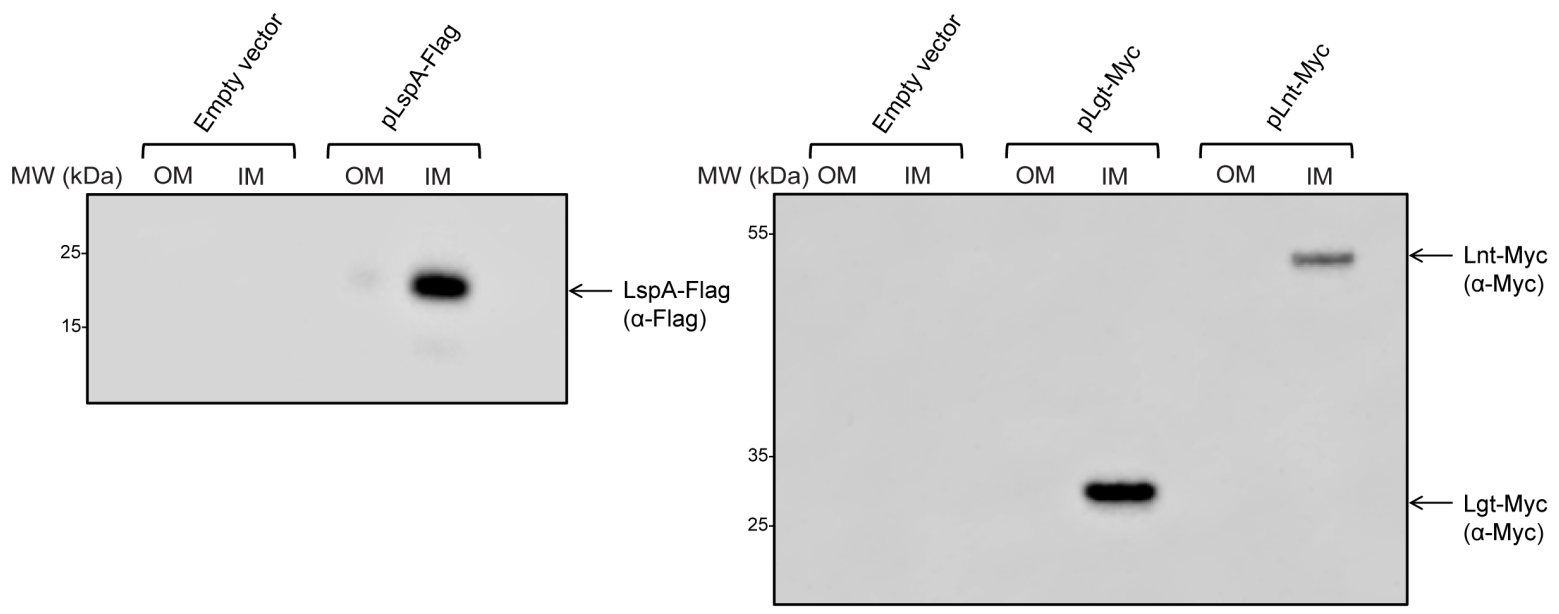

b

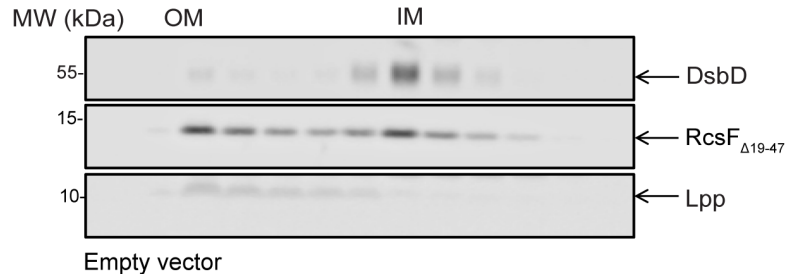

Empty vector

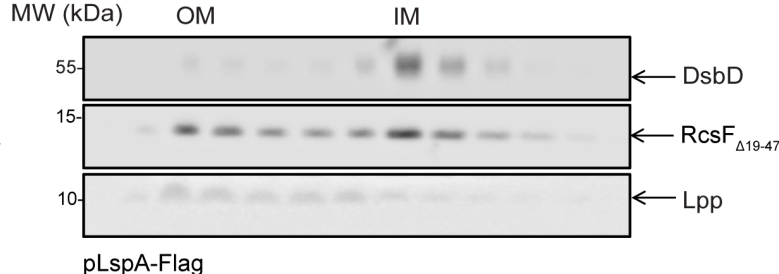

pLspA-Flag

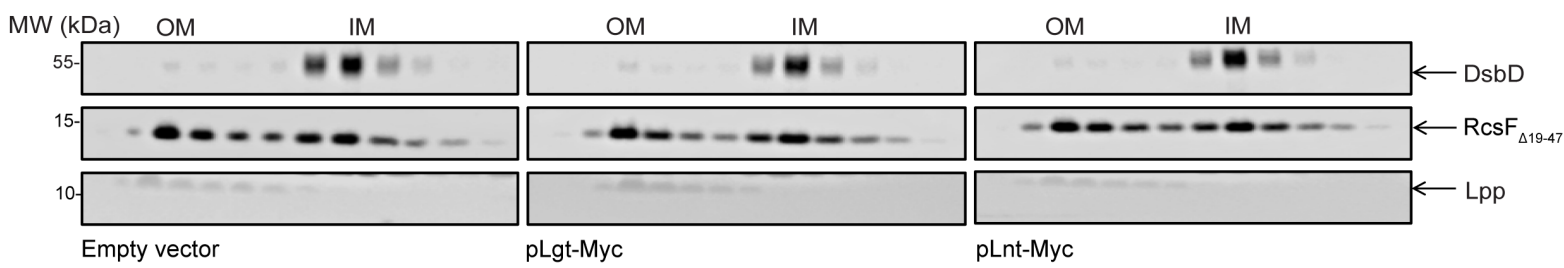


851 Extended Data Table 1: List of the verified lipoproteins of $E$. coli used for the structural 852 analysis in this study.

853 Attached Excel sheet

854

855 Extended Data Table 2: ResF mutants used in this study and the amino acid sequences of

856 their corresponding N-terminal linkers. The acylated cysteine is the first residue listed.

\begin{tabular}{|l|l|}
\hline ResF linkers & \multicolumn{1}{c|}{ Amino acid sequence } \\
\hline RcsF $_{\mathrm{WT}}$ & CSMLSRSPVEPVQSTAPQPKAEPAKPKAPRATPV \\
\hline $\mathrm{RcsF}_{\Delta 19-47}$ & CSMGPV \\
\hline $\mathrm{RcsF}_{\mathrm{GS}}$ & CSMSLFDAPAMSGSGSGAMSGSGSGAMPV \\
\hline $\mathrm{RcsF}_{\mathrm{GS} 2}$ & CSMSGSGSGAMSGSGSGAMPV \\
\hline $\mathrm{RcsF}_{\mathrm{GS} 3}$ & CSMSGSGSGAMPV \\
\hline $\mathrm{RcsF}_{\mathrm{FkpA}}$ & CSMGSDQEIEQTLQAFEARVKSSAQAKMEKDAADNEPV \\
\hline $\mathrm{RcsF}_{\mathrm{col}}$ & $\begin{array}{l}\text { CSMGILDTRLSELEKNGGAALAVLDAQQARLLGQQTRNDRAISEARNKL } \\
\text { SSVTESLNTARNALTRAEQQLTQQKPV }\end{array}$ \\
\hline
\end{tabular}

857 
Extended Data Table 3: $E$. coli strains used in this study.

\begin{tabular}{|c|c|c|}
\hline Strains & Genotype and description & Source \\
\hline DH300 & rprA-lacZ MG1655 (argF-lac) U169 & 47 \\
\hline $\begin{array}{l}\text { Keio collection } \\
\text { single mutants }\end{array}$ & rcsF $:: k a n$, rcsB $:: k a n$, pal::kan, nlpD::kan, envC::kan & 48 \\
\hline XL1-Blue & $\begin{array}{l}\text { endA1 gyrA96 }\left(\mathrm{nal}^{\mathrm{R}}\right) \text { thi-1 recA1 relA1 lac glnV44F' } \\
{\left[\because \operatorname{Tn} 10 \text { proAB }{ }^{+} \text {lacl }^{q} \Delta(\mathrm{lacZ}) \mathrm{M} 15\right] \text { hsdR } 17\left(\mathrm{r}_{\mathrm{K}}^{-} \mathrm{m}_{\mathrm{K}}^{+}\right)}\end{array}$ & Stratagene \\
\hline BL21 & F- ompT hsdSB (rB- mB-) gal dcm (DE3) & Novagen \\
\hline JS41 & DH300 $\Delta r c s F$ pAM238 & This study \\
\hline JS265 & DH300 $\Delta r c s F$ pJS18 & This study \\
\hline JS346 & DH300 $\Delta r c s F r c s B:: k a n$ pET22b & This study \\
\hline JS267 & JS346 pJS18 & This study \\
\hline JS325 & DH300 pal::kan & This study \\
\hline JS331 & JS325 pJS20 & This study \\
\hline JS345 & JS325 pJS24 & This study \\
\hline JS360 & DH300 $\Delta r c s F$ pJS27 & This study \\
\hline JS363 & JS346 pJS27 & This study \\
\hline JS364 & DH300 $\Delta r c s F$ pSC202 & This study \\
\hline JS372 & DH300 $\Delta r c s F$ pSC201 & This study \\
\hline JS395 & JS346 pSC198 & This study \\
\hline JS396 & JS346 pSC199 & This study \\
\hline JS397 & JS346 pSC200 & This study \\
\hline JS398 & JS346 pSC201 & This study \\
\hline JS573 & JS346 pSC202 & This study \\
\hline JS574 & DH300 $\Delta r c s F$ pSC198 & This study \\
\hline JS575 & DH300 $\Delta r c s F$ pSC199 & This study \\
\hline
\end{tabular}




\begin{tabular}{|c|c|c|}
\hline JS576 & DH300 $\Delta r c s F$ pSC200 & This study \\
\hline JS639 & $\Delta r c s B$ lpp::kan rcsF::rcs $F_{\Delta 19-47}$ & This study \\
\hline JR30 & nlpD::kan & This study \\
\hline JR31 & JR30 pJR8 & This study \\
\hline JR32 & JR30 pJR10 & This study \\
\hline JR2 & DH300 pAM238 & This study \\
\hline JR88 & BL21 rcsF ::kan & This study \\
\hline JR90 & JR88 pET28-cytoplasmic LolB-Strep & This study \\
\hline JR187 & rcs $B:: k a n$ rcsF $: \because r c s F_{\Delta 19-47}$ & This study \\
\hline JR149 & $\Delta n l p D$ & This study \\
\hline JR121 & $\Delta n l p D$ envC::kan & This study \\
\hline JR122 & JR121 pJR8 & This study \\
\hline JR123 & JR121 pJR10 & This study \\
\hline JR188 & JR187 pAM238 & This study \\
\hline JR191 & JR187 pAG833 & This study \\
\hline JR204 & JR187 pJR203 & This study \\
\hline JR194 & JR187 pBAD33 & This study \\
\hline JR211 & JR187 pJR209 & This study \\
\hline JR257 & JR187 pJR239 & This study \\
\hline JR274 & JR149 lpp::kan & This study \\
\hline JR279 & JR274 pJR10 & This study \\
\hline JR292 & JS325 pAM238 & This study \\
\hline JR293 & JR187 pSC213 & This study \\
\hline JR44 & rcs $B:: k a n \operatorname{rcs} F:: r c s F_{\Delta 19-47} \mathrm{pJR} 48$ & This study \\
\hline
\end{tabular}


bioRxiv preprint doi: https://doi.org/10.1101/2021.01.05.425367; this version posted January 5, 2021. The copyright holder for this preprint (which was not certified by peer review) is the author/funder, who has granted bioRxiv a license to display the preprint in perpetuity. It is made available under aCC-BY-NC-ND 4.0 International license.

861

\begin{tabular}{|l|l|l|}
\hline JR47 & $r c s B::$ kan $\mathrm{pJR} 48$ & This study \\
\hline JR77 & $\operatorname{rcsB}::$ kan $r c s F: \because r c s F_{\Delta 19-47} \mathrm{pBAD} 18$ & This study \\
\hline JR78 & $\operatorname{rcsB}::$ kan $\mathrm{pBAD} 18$ & This study \\
\hline
\end{tabular}

862 
Extended Data Table 4: Plasmids used in this study.

\begin{tabular}{|c|c|c|}
\hline Plasmids & Features & Source \\
\hline pAM238 & $\begin{array}{l}\text { IPTG-regulated } \mathrm{P}_{\text {lac }}, \mathrm{pSC} 101-\text { based, spectinomycin (no } \\
\text { lacIQ) }\end{array}$ & 50 \\
\hline pBAD18 & Arabinose inducible $\mathrm{P}_{\mathrm{BAD}}$, ampicillin & 56 \\
\hline pBAD33 & Arabinose inducible $\mathrm{P}_{\mathrm{BAD}}$, chloramphenicol & 56 \\
\hline pET28a & IPTG regulated T7 promoter, kanamycin & Novagen \\
\hline $\mathrm{pET} 22 \mathrm{~b}$ & IPTG regulated T7 promoter, ampicillin & Novagen \\
\hline $\mathrm{pCP} 20$ & $\mathrm{FLP}^{+}, \lambda c \mathrm{I} 857^{+}, \lambda$ PR $\mathrm{Rep}^{\mathrm{ts}}$, ampicillin, chloramphenicol & 49 \\
\hline pSIM5-Tet & $\begin{array}{l}\text { pSC101 plasmid, repAt } \mathrm{t}^{\mathrm{s}} \text {, tetRA, } \lambda \text {-Red (Gram-Beta-Exo), } \\
c \mathrm{I} 857 \text {, tetracycline }\end{array}$ & $\begin{array}{l}\text { Gift from D. } \\
\text { Hughes }\end{array}$ \\
\hline pJS18 & pAM238 RcsF FKpA $_{\text {FkpA linker (S94-E125) }}$ & This study \\
\hline pJS20 & pAM238 $\mathrm{Pal}_{\mathrm{WT}}$ & This study \\
\hline pJS24 & pAM238 $\mathrm{Pal}_{\Delta 26-56}$ & This study \\
\hline pJS27 & pAM238 RcsF col $_{\text {Colicin Ia linker (I213-K282) }}$ & This study \\
\hline pSC198 & pAM238 RcsF $\mathrm{GS}_{3}\left(\mathrm{C}_{16} \mathrm{~S}_{17} \mathrm{M}_{18} \mathrm{~S}_{19}\right.$ GSGSGAMG $)$ & This study \\
\hline pSC199 & $\begin{array}{l}\text { pAM238 } \operatorname{RcsF}_{\mathrm{GS} 2}\left(\mathrm{C}_{16} \mathrm{~S}_{17} \mathrm{M}_{18} \mathrm{~S}_{19} \mathrm{GSGSGAMSGSGSGAM}\right. \\
\mathrm{G})\end{array}$ & This study \\
\hline pSC200 & $\begin{array}{l}\text { pAM238 RcsF }{ }_{G S}\left(\mathrm{C}_{16} \mathrm{~S}_{17} \mathrm{M}_{18} \mathrm{~S}_{19} \text { LFDAPAMSGSGSGAM }\right. \\
\text { SGSGSGAMG) }\end{array}$ & This study \\
\hline pSC201 & pAM238 $\operatorname{RcsF}_{\Delta 19-47}\left(\mathrm{C}_{16} \mathrm{~S}_{17} \mathrm{M}_{18} \mathrm{G}_{19} \mathrm{P}_{20}\right)$ & This study \\
\hline pSC202 & pAM238 RcsF ${ }_{W T}$ & This study \\
\hline pJR8 & pAM238 NlpD ${ }_{\mathrm{WT}}$ & This study \\
\hline pJR10 & pAM238 NlpD $\mathrm{D}_{\Delta 29-64}\left(\mathrm{C}_{26} \mathrm{~S}_{27} \mathrm{D}_{28} \mathrm{~A}_{29}\right)$ & This study \\
\hline pJR48 & pBAD18 LolA-6xHis & This study \\
\hline pJR90 & pET28 Cytoplasmic LolB-Strep & This study \\
\hline
\end{tabular}




\begin{tabular}{|l|l|l|}
\hline pJR203 & pBAD33 LolCDE-6xHis & This study \\
\hline pJR209 & pAM238 Lnt-Myc & This study \\
\hline pJR239 & pSC213 LspA-Flag & This study \\
\hline pSC213 & pAM238, IPTG-regulated Plac $_{\text {lacIQ, triple Flag tag }}$ & This study \\
\hline pAG833 & pAM238 Lgt-Myc & This study \\
\hline
\end{tabular}

Extended Data Table 5: Primers used in this study.

\begin{tabular}{|l|l|}
\hline \multicolumn{1}{|c|}{ Primer } & \\
\hline $\begin{array}{l}\text { JS50_FkpAlinker } \\
\text { fw }\end{array}$ & acatccatggggtccgaccaagagatcgaac \\
\hline $\begin{array}{l}\text { JS51_FkpAlinker } \\
\text { rv }\end{array}$ & atgtcggaccggttcgttatcagccgcgtc \\
\hline $\begin{array}{l}\text { JS143_Pal_-100b 3' } \\
\text { JS144_Pal_+100b }\end{array}$ & tgtcttccggcaactgatgg \\
\hline $\begin{array}{l}\text { JS145_Pal_fw } \\
\text { thgtgctgagcaaagcg }\end{array}$ & ACATggtaccTTAATTGAATAGTAAAGGAATC \\
\hline $\begin{array}{l}\text { JS146_Pal_rv } \\
\text { JS152_PalNoLink } \\
\text { fw }\end{array}$ & ATGTtctagaTTAgtaaaccagtaccgcac \\
\hline $\begin{array}{l}\text { JS153_PalNoLink } \\
\text { er_overlapPCR_ } \\
\text { rv }\end{array}$ & CAGACGAccaacCAGGCTCGTCTGCAAATG \\
\hline $\begin{array}{l}\text { JS277_LolCDEHi } \\
\text { s_fw }\end{array}$ & ACATtctagaTCTTTGCTACAGCAACCAGAC \\
\hline $\begin{array}{l}\text { JS278_LolCDE_ } \\
\text { His_rv }\end{array}$ & ATGTctgcagTTAGTGATGGTGATGGTGATGACCctggccgctaaggactcg \\
\hline $\begin{array}{l}\text { JS289_lred_catSa } \\
\text { cBin_RcsF_fw }\end{array}$ & $\begin{array}{l}\text { tcctgattcaatattgacgttttgatcatacattgaggaaatactAAAATGAGACGTTGATCGG } \\
\text { CACG }\end{array}$ \\
\hline
\end{tabular}




\begin{tabular}{|c|c|}
\hline $\begin{array}{l}\text { JS290_lred_catSa } \\
\text { cBin_RcsF_rev }\end{array}$ & $\begin{array}{l}\text { tatagggegagcgaataacgectatttgctcgaactggaaactgcATCAAAGGGAAAACTGT } \\
\text { CCA }\end{array}$ \\
\hline $\begin{array}{l}\text { JS291_lred_RcsF } \\
\text { catSacBout_fw }\end{array}$ & $\begin{array}{l}\text { tcctgattcaatattgacgttttgatcatacattgaggaaatactATGCGTGCTTTACCGATCTG } \\
\text { TT }\end{array}$ \\
\hline $\begin{array}{l}\text { JS292_lred_RcsF } \\
\text { catSacBout_rv }\end{array}$ & $\begin{array}{l}\text { tatagggegagcgaataacgectatttgctcgaactggaaactgcTCATTTCGCCGTAATGTT } \\
\text { AAGC }\end{array}$ \\
\hline $\begin{array}{l}\text { JS293_junction } 11 \text { r } \\
\text { ed_RcsFup_fw }\end{array}$ & gcggagctgttaaaggctg \\
\hline $\begin{array}{l}\text { JS294_junction21r } \\
\text { ed_RcsFdown_rv }\end{array}$ & gagcaatgagatgcagttcg \\
\hline $\begin{array}{l}\text { JS295_junction } 11 \mathrm{r} \\
\text { ed_cat-out_rv }\end{array}$ & CGGGCAAGAATGTGAATAAAGG \\
\hline $\begin{array}{l}\text { JS296_junction21r } \\
\text { ed_sacB-out_fw }\end{array}$ & GCTGTACCTCAAGCGAAAGG \\
\hline M13R & CAGGAAACAGCTATGACCATG \\
\hline M13F & TGTAAAACGACGGCCAGT \\
\hline $\begin{array}{l}\text { PL145_rcsF_- } \\
100 \mathrm{~b}\end{array}$ & cgctttttaccagacctggc \\
\hline $\begin{array}{l}\text { PL146_rcsF_+10 } \\
0\end{array}$ & atatcattcaggacgggcgcttgccc \\
\hline $\begin{array}{l}\text { PL153_rcsB_- } \\
100 b\end{array}$ & acatctgattcgtgagaagg \\
\hline $\begin{array}{l}\text { PL154_rcsB+100 } \\
b\end{array}$ & taatgggaatcgtaggccgg \\
\hline $\begin{array}{l}\text { PL168_Fw_lpp_- } \\
100\end{array}$ & CAATTTTTTTATCTAAAACCCAGCG \\
\hline $\begin{array}{l}\text { PL169_Rv_lpp_+ } \\
100\end{array}$ & CCAGAGCAAGGGAATATGTTACGCG \\
\hline SH_Da linker_F & CATGaGcTTATTCGACGCGCCGGc \\
\hline SH_Da linker_R & catggCCGGCGCGTCGAATAAgCt \\
\hline SH_RcsF(PstI)_R & gagaCTGCAGtcaTTTCGCCGTAATGTTAAG \\
\hline $\begin{array}{l}\text { SH_RcsFUR(kpn } \\
\text { I)_F }\end{array}$ & GAGGGTACCcgttttgatcatacattg \\
\hline $\begin{array}{l}\text { RcsFss-Fsg } \\
(\mathrm{NcoI}) \_\mathrm{F}\end{array}$ & GCGGCTGTTCCATGGggccggtccgaatttatac \\
\hline $\begin{array}{l}\text { RcsFss-Fsg } \\
(\mathrm{NcoI}) \_\mathrm{R}\end{array}$ & ggaccggccCCATGGAACAGCCGCTTAGCATGAG \\
\hline SH_GS linker_F & CATGagtggctctggatctggtgc \\
\hline
\end{tabular}




\begin{tabular}{|c|c|}
\hline SH_GS linker_R & catggcaccagatccagagccact \\
\hline JR1_NlpD_fw & GAGATCTAGATTATTAACCAATTTTTCCTGGGGGATAA \\
\hline JR2_NlpD_rv & AGAGCTGCAGTTATCGCTGCGGCAAATAACGCA \\
\hline $\begin{array}{l}\text { JR7_NlpDoverlap } \\
\text { fw }\end{array}$ & GGCTGGCAGGCTGTTCTGACGCGCAGCAACCGCAAATTCA \\
\hline $\begin{array}{l}\text { JR8_NlpDoverlap } \\
\text { rv }\end{array}$ & TGAATTTGCGGTTGCTGCGCGTCAGAACAGCCTGCCAGCC \\
\hline $\begin{array}{l}\text { JR23_Fw_NlpD- } \\
98\end{array}$ & CAGGTCAGCGTATCGTGAACATC \\
\hline $\begin{array}{l}\text { JR24_Rv_NlpD+ } \\
100\end{array}$ & TCATTTAAATCATGAACTTTCAGCG \\
\hline $\begin{array}{l}\text { JR30_Fw_LolA_- } \\
28 \_ \text {BBAD18 }\end{array}$ & ACATGGTACCCGGGAGTGACGTAATTTGAGGAAT \\
\hline $\begin{array}{l}\text { JR31_Rev_LolA_ } \\
\text { His_pBAD18 }\end{array}$ & $\begin{array}{l}\text { ATGTTCTAGAttaatgatgatgatgatgatgctcgaGCTTACGTTGATCATCTACC } \\
\text { GTGAC }\end{array}$ \\
\hline $\begin{array}{l}\text { JR50_Rev_cytopl } \\
\text { asmic_LolB_nost } \\
\text { op_StrepTag_stop }\end{array}$ & $\begin{array}{l}\text { CCAACTCGAGTCACTTTTCGAACTGCGGGTGGCTCCAGCTTGCTTT } \\
\text { CACTATCCAGTTATCCAT }\end{array}$ \\
\hline $\begin{array}{l}\text { JR56-Fw--100- } \\
\text { envC }\end{array}$ & GTTGTCGCTG ATGGGTA \\
\hline $\begin{array}{l}\text { JR57-Rev- } \\
+100 \text { envC }\end{array}$ & AATCATCAATGACGATGGCA \\
\hline $\begin{array}{l}\text { JR74-Rev-Lnt- } \\
\text { myctag-PstI }\end{array}$ & $\begin{array}{l}\text { AAAAACTGCAGctacaggtcttcttcgctaatcagtttctgttcgettgcTTTACGTCGCTG } \\
\text { ACGCAGAC }\end{array}$ \\
\hline $\begin{array}{l}\text { JR77-Fw-NcoI- } \\
\text { LspA }\end{array}$ & gagaCCATGGgtAGTCAATCGATCTGTTCAAC \\
\hline $\begin{array}{l}\text { JR78-Rev-LspA- } \\
\text { no stop-BamHI }\end{array}$ & gagaGGATCCTTGTTTTTTCGCTCTAG \\
\hline $\begin{array}{l}\text { AG389_lgt_- } \\
\text { 49_Fw_KpnI }\end{array}$ & AAAAAggtaccTTCAATCGCTGTTCTCTTTC \\
\hline $\begin{array}{l}\text { AG393_lnt_- } \\
\text { 49_Fw_KpnI }\end{array}$ & AAAAAggtaccACCCCAGCCGAAGCTGGATG \\
\hline $\begin{array}{l}\text { AG403_lgt_myc } \\
\text { CT_PstI }\end{array}$ & $\begin{array}{l}\text { AAAAACTGCAGctacaggtcttcttcgctaatcagtttctgttcgcttgcGGAAACGTGTT } \\
\text { GCTGTGGGC }\end{array}$ \\
\hline $\begin{array}{l}\text { PL387- } \\
\text { LolBwoss-Fw- } \\
\text { NcoI }\end{array}$ & acacCCATGGccgttaccacgcccaaagg \\
\hline $\begin{array}{l}\text { ColicinIalinker } \\
\text { geneBLOCK }\end{array}$ & $\begin{array}{l}\text { acatccatggggATTCTGGACACGCGGTTGTCAGAGCTGGAAAAAAATG } \\
\text { GCGGGGCAGCCCTTGCCGTTCTTGATGCACAACAGGCCCGTCTGC } \\
\text { TCGGGCAGCAGACACGGAATGACAGGGCCATTTCAGAGGCACGG } \\
\text { AATAAACTCAGTTCAGTGACGGAATCGCTTAACACGGCCCGTAAT }\end{array}$ \\
\hline
\end{tabular}


bioRxiv preprint doi: https://doi.org/10.1101/2021.01.05.425367; this version posted January 5, 2021. The copyright holder for this preprint (which was not certified by peer review) is the author/funder, who has granted bioRxiv a license to display the preprint in perpetuity. It is made available under aCC-BY-NC-ND 4.0 International license.

869

GCATTAACCAGAGCTGAACAACAGCTGACGCAACAGAAAgcggtccg acat 
bioRxiv preprint doi: https://doi.org/10.1101/2021.01.05.425367; this version posted January 5, 2021. The copyright holder for this preprint (which was not certified by peer review) is the author/funder, who has granted bioRxiv a license to display the preprint in perpetuity. It is made available under aCC-BY-NC-ND 4.0 International license. 